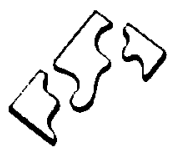

\title{
Phenomenology and Human Science Reconsidered
}

\author{
Robert Burch \\ Past Cross-Department Professor \\ Department of Secondary Education \\ Department of Philosophy \\ University of Alberta
}

When asked to write a biographical sketch, I thought the task would be a relatively easy one-a sentence or two about how I got interested in human science research, a few remarks about how that interest developed, a couple more sentences about how it led to an association with the Faculty of Education and with Phenomenology + Pedagogy, and some final words about my current research, all quite short and to the point. Though I began with these good intentions, every attempt to fulfill them evolved very quickly into a réecherche du temps perdu. When I then tried to confine these reflections and extract some key points, the result was a caricature in which I could not clearly see myself, I thought of Woody Allen's joke: "Suddenly my while life passed before me ... but it was somebody else's life!" Still, in the very failure of my intentions, something at least about the tenor and habit of my thinking has perhaps been revealed.

Instead of giving the details of a curriculum vitae, I should like to use this occasion for two gestures of acknowledgement long overdue. The first is to Ted Aoki. When I was beginning my researches in the philosophy of technology (to the puzzlement and sometimes barely concealed derision of many of my philosophy colleagues), Ted, who was then the chair of the Department of Secondary Education, offered me the opportunity to pursue that interest in a sequence of graduate seminars in his department. I am grateful for that opportunity and for all that came of those seminars over the years, having received, I suspect, much more than I have given. But I am also grateful for what the offer itself embodied. In a context where people have tended more and more to see only impediments and to bemoan what cannot be done, Ted has seen possibilities and has found ways to make them actual. By this continued example, he has shown what a genuine community of scholars ought and can be. The second is to Max van Manen. Through the encouragement of human science projects, the organizing of discussion groups, and above all the founding and sustaining of Phenomenology + Pedagogy, Max has kept open a space in which reflection upon "the things themselves" should originate and develop. It has been in that space also that I was afforded the freedom and the challenge to explore where I truly stand philosophically, in a way, ironically, that was not granted within the confines of a Philosophy Department alone. My thinking and understanding would have been the lesser without Max's efforts.

"The knowledge of spirit is the most concrete and for that reason the highest and most difficult knowledge" (Hegel, 1978, p. 3). 
The following paper recapitulates and carries forward a suite of formal explorations on the topic of phenomenological method began in "On Phenomenology and Its Practices" (Burch, 1989) and continued in "Lived Experience/Phenomenology: Taking a Measure of the Topic" (Burch, 1990). In the first paper, I sketched the formal conditions under which as radical philosophy is first intelligible and defensible and from that perspective charted the basic consequences which these conditions have for a preliminary, general conception of phenomenological theorizing. In the second paper, I traced the fundamental determinations of lived experience in order to begin to show how the phenomenological orientation being outlined has a basis in lived experience as such and hence to provide that orientation with some formal legitimation. Of my initial project (Burch, 1989, pp. 189-90), two theoretical tasks still remain.

The first is to consider more originally and inclusively the meaning of the phenomenological orientation so far plotted with a view to tracing more closely the ways in which phenomenological theorizing is in principle oriented to its topic. This brings full circle the purely formal consideration of phenomenology as such, providing a concluding step in the reflective movement from formal conditions, to existential/ontological grounds as such, to formal conditions reinterpreted. Insofar as this movement is merely formal, it admits of closure and so can be judged as to its "correctness" on standards of completeness and consistency. Nevertheless, such considerations must themselves be situated and assessed in the whole ongoing process of phenomenological reflection, a process which, "as it proceeds to disclose its subject-matter more essentially ... must necessarily appropriate and reappropriate its own beginning and the previous course of its thought" (Burch 1989, p. 193). It is in and through this process, and by means of any merely formal considerations alone, that the self-definition and self-legitimation of phenomenology is "truly" accomplished, as the "truth" of phenomenology itself is realized. ${ }^{1}$ In having a systematic, comprehensive purpose prior to the concrete relation of phenomenology and pedagogy, this entire suite of methodological considerations properly begins and concludes with what is formal and determinate. In truth, however, the methodological considerations of phenomenology always essentially remain incomplete as long as one continues to be engaged in phenomenological explorations.

My second task is to consider in principle the meaning of the phenomenological orientation being sketched for all human science research that would take from phenomenology its specific methodological directive, and in this way to map out a distinctive domain of "scientific" investigation. Despite how this may at first seem, the strategy is not simply to apply preestablished rules of phenomenological inquiry to a given set of problems, as if phenomenological method were a formal apparatus external to whatever if may be turned to interrogate. Instead, my procedure is to explore the essence of our thinking concerning human reality insofar 


\section{University of Alberta}

as, qua phenomenological, this thinking is able to correspond to what is truly questionable in the essence of subject matter itself. That this conflicts with the prevailing conception of "scientific research," I would not deny. Yet it is the hegemony of that conception, and hence the appropriateness of its universal application, that is chiefly at issue.

\section{On the Topic and Procedures of Phenomenology}

"In what is most its own, phenomenology is not a school. It is the possibility of thinking, at times changing and only thus persisting, of corresponding to the claim of what is to be thought" (Heidegger, 1972, p. 65).

Insofar as lived experience is essentially a "self-constituting process" (Burch, 1990, pp. 135-37), a phenomenology oriented to lived experience essentially should take its initial bearings from what that process actually accomplishes. Where such investigation begins with what is most rudimentary, it looks to the way in which a spatial/temporal horizon is first opened up existentially, before the objective measures of chronology and geometry. The opening up of such a horizon is concomitant with the very origins of our selfhood, the self of lived experience coming to realize itself first and foremost in and through the process of its embodied, pragmatic engagement with the world. But insofar as every lived experience is always someone's experience from some place, a spatial/temporal dimension persists throughout, whatever the particular focal content or truth of the experience. Thus, in maintaining a perspective on lived experience, phenomenology must differentiate those experiences in which the dimension of lived space and time is central to its particular intelligibility and to explore concretely how that is so, and those where it is not. Similarly, insofar as the self of lived experience is in its self-constitution essentially situated, phenomenology must in the first place also establish in each case the relevant constitutive natural, historical, and anthropological "facts" that limit and enable the experience being explored, those that belong intrinsically to its particular intelligibility.

That lived experience is essentially a self-constituting process also requires that phenomenology interpret lived experience in existential/ontological rather than merely subjective or objective terms. The issue is not simply one concerning the meanings one understands or what one's experiences are like, nor even less the determination of one's objective circumstances, but of how in the essential interplay between one's situation and the course of her lived experience one comes to be who she is. Thus, for example, in Hegel's essential account of the master/slave relation (1977), the slave is revealed not just as a person who behaves as a slave, who is objectively subjugated and has a slavish outlook. Rather, in all of this, the person is slave; this defines her very being. Moreover, to raise herself beyond slavery requires not just a change of circumstances (which others might well effect for her) or of intentions (which one might well take over from what others say, without making truly her own), but 
more fundamentally an ontological self-transformation and hence an existential-ontological reorientation.

Insofar as the self in lived experience is essentially an embodied self, phenomenological analysis must consider too the meaning of "bodily" being, not merely as an adjunct to consciousness in general, but as existentially/ontologically original. Accordingly, it must consider from the start all of the essential ways in which we are meaningfully "attuned" to the world, and thus both how the body is "lived," and through the lived body how things claim and are claimed by us. This too concerns not just experiences we have but who we are. For what lived experience is

never remains external and accidental to it, since this is always taken up and integrated into it.... Therefore the body in general ... ought not to be regarded as a fortuitous content of our experience. Existence has no fortuitous attributes, no content which does not contribute to giving it its form.(Merleau-Ponty, 1962, p. 169)

This is the thesis of self-constitution specified in terms of embodiment. In this regard, the relations that hold in general for phenomenology (e.g., between the particular and the universal or between existential understanding and phenomenological interpretation) come into play again. But they do so not as abstract determinations clearly delineated in advance but as relations to be decided in and through lived experience and the actual processes of its phenomenological analysis. This involves a complex web of issues concerning the essence of embodiment. It includes, for example, how the concrete meanings of embodiment are constituted in the essential unity of general meanings that pertain to the lived body as such (i.e., the corps propre as anonymous and prepersonal) and the specific meanings that pertain to a particular lived body (i.e., the corps propre as one's own, individual and individuating); how in particular cases certain meanings (e.g., masculine, obese, handicapped) are inscribed on the lived body in the context of specific natural, historical and anthropological "facts" and interpretations; how the key metaphors and tropes, indeed the whole affective space of a phenomenological interpretation is conditioned by specific meanings that obtain within the embodied existence of the interpreter herself. ${ }^{2}$

Insofar as the self's self-constitution is specified in the first place in terms of embodiment, the self in lived experience also "must be conceived, not theoretically as subject, but practically as agent" (Macmurray, 1956, p. 38). In this respect, the question of what this self is (i.e., its self-constitution) cannot be separated from the whole way in which in everyday terms it is actively directed to and engaged in the world. The meanings realized in lived experience are first and foremost pragmatic, and where there is no agency, there is no selfhood.

At the same level of lived experience, the self also "is comprehensible only in terms of a dynamic social reference" (p. 38). 


\section{University of Alberta}

The infant is, from the very beginning, not just an individual organism (though the "organic" enters into all human behaviour) but a person in relation to another person. Persons "are constituted by their mutual relation to each other. 'I' exist only as one element in a complex 'You' and 'I'.... Human behaviour carries always, in its inherent structure, a reference to the personal other. (Macmurray, 1961, p. 61; quoted in Schmidt, 1983, p. 70)

Thus, precisely in its concern for the integrity of the other's selfhood, phenomenology must attend at the most basic level to how that experience and self are socially constituted.

A person has parents, siblings, other relations, friends etc., all of whom ... are not merely people out there, external to him, but constitute ... his concrete actuality, the actual heart of him. When such people die, a part of his actuality dies. (Hegel, 1978, p. 273)

Where originally there is no intersubjectivity, there is no selfhood. No doubt, from the standpoint of reflective self-consciousness, these others are apt to "appear as an external circle" separate from whom I think myself truly to be. Existentially/ontologically, however, they constitute part of "the essential actuality of my self" (p. 273).

But, as we have discovered, the meaning and ground of lived experience does not lie exclusively nor principally in the relations we take up as embodied selves to things within the world. The natural, historical and anthropological facts that enter into our self-constitution, the objects of theory and practice to which we direct ourselves, indeed our whole being in the midst of beings, is grounded in the transcendence that is our being-in-the-world. "This world, and the sub-worlds of meaning contained within it, make up at any given time our 'hermeneutic situation'" (Burch, 1989, p. 208). Thus, in situating these relations and in determining their existential/ontological meaning, it is an understanding of the "hermeneutic situation" that serves us phenomenologically as "the ultimate referent and guide" (p. 208). Moreover, this holds both for the attempt to discover the essential truth of particular experiences, as well as for assessing the truth of the phenomenology that does the discovering.

In the intelligibility of any lived experience, there is usually a manifold of fundamental determinations and sememic threads, the self-constitution of the experience being a complex, concrete process. Thus, on the one hand, although oriented above all to the hermeneutic situation, phenomenology must focus on those "determinations" and "threads" that contribute most to the unique meaning of the experience. On the other hand, the varied dimensions that phenomenology traces "are not mutually exclusive, nor can they be discussed separately from one another" (Barritt, Beekman, Bleeker, \& Mulderij, 1983, p. 157). Over and above its internal articulations, lived experience itself is "a unitary phenomenon" and "must be seen as a whole" (Heidegger, 1977a, p. 53). Ideally, then, 
the essential dimensions of lived experience should be surveyed in a single synoptic vision, grasping at once all of the relevant "determinations" and "threads" from the vantage point of one's understanding of the "whole" situation. However, since phenomenology can only ever explore these dimensions serially, it must proceed systematically, giving hints as to what has been left unsaid and revising its story as it proceeds, keeping the whole always in mind. But to recover in this way what is peculiarly determinative of a lived experience, phenomenology must also be guided from the start by a thematic sense, a prior vision of what is essential. For only in terms of such a sense could the various constitutive dimensions of a lived experience as such be revealed and related in the first place, and the experience itself be recollected in its own peculiar integrity. Of course, in being faithful to our lived experience, phenomenology is prohibited from simply constructing or inventing a convenient unifying and directing meaning. Rather, it must appropriate a sense from what has already been understood, however obscurely or tacitly, within the experience itself.

Thus far, I have drawn the distinction between lived experience and phenomenological interpretation rather sharply. It is important to note, however, that the actual course of phenomenological theorizing is itself a lived experience with its own existential sense. Thus not only may we situate lived experiences phenomenologically, we may also situate phenomenological theorizing and ask ourselves phenomenologically "where are we when we think?" (cf. Arendt, 1978). With this question, we are asking not only about the place of our theorizing in terms of its ground in a prior existential understanding and about the truth of its explicit narrative, although that is a crucial part of it. We are also concerned about the experience of thinking itself and hence about where we stand and who we are in the very process of our theorizing. To a theorizing that is pedagogically oriented, this is an equally crucial issue.

\section{The Meaning of the Phenomenological Orientation}

From what we have disclosed thus far, the meaning of phenomenology can be brought more originally into focus. In the writing about phenomenology, this meaning is typically encapsulated in three familiar maxims:

"Phenomenology is the study of essences; and according to it, all problems amount to finding definitions of essences" (Merleau-Ponty, 1962, p. vii).

Phenomenology enjoins us to attend directly "to the things themselves [zu dem Sachen selbst]" (Husserl, 1965, p. 146).

"The expression 'phenomenology' signifies primarily a concept of meth$o d$ " (Heidegger, 1977a, p. 27).

Of these maxims, the second is pivotal. What distinguishes genuine phenomenology above all, Husserl (1965) insists, is that it be concerned not with "philosophies" but with the "things themselves" (p. 146). And it 


\section{University of Alberta}

is with respect to the "things themselves" that the methodological procedures and the essential discoveries of phenomenology must be decided. But this belies Husserl's injunction. For the question of the "things themselves" is not an immediate given but a "philosophical" issue, the discussion of which has its own place in the philosophical tradition. In this respect, phenomenological rigor makes engagement with that tradition in determining what phenomenology is unavoidable.

\section{The Study of Essences}

Since Plato began in the Socratic dialogues to ask specifically about the eide of various things (e.g., of justice, piety, etc.), the search for "essences" has been a general feature of philosophical inquiry, (and the assumption of all skeptical/nominalist attacks), and not a specific innovation of phenomenology. "According to ancient doctrine, the essence of a thing is considered to be what the thing is" (Heidegger, 1977b, p. 4), that is, a fixed, universal, selfsame and univocal quality that informs the thing as such, at once the ground of its being and its being intelligible. The search for this "whatness" was to serve a threefold purpose: to define the categories, principles, or ideas that determine each thing as such (e.g., that in virtue of which justice is justice, a tree is a tree, etc.); to delimit the general idea or type by means of which many instances of the same thing could be known and classified as the same (e.g., the oak, maple, redwood all as trees); and to specify the fixed and universal measure in terms of which a multiplicity of things could be judged, discriminating the "true" instances from the sham. Presupposed in this doctrine is a conceptual division of essence and existence (and hence of "whatness" and "thatness," possibility and actuality), a priority of essence in determining the being of beings in themselves, and a notion of "truth" as the conformity of the existent thing to its essence, upon which is grounded "truth" as the correspondence of our essential knowledge with the thing. This doctrine is also said to be "onto-theological" (Heidegger, 1957), insofar as it considers beings as beings in terms of what is "highest and most general" in the realm of beings, that is, in terms of God as the one necessary being (summum ens, ens realissimum) in which essence entails existence, in which there is no discrepancy between possibility and actuality, and wherein truth is fully realized. As the highest and most general being, God is at once the causal source and the ground of the intelligibility of all that is actual.

However much it may be tied to "onto-theology" by a concern for essence, phenomenology is nonetheless distinctive in that it "put[s] essences back into existence" (Merleau-Ponty, 1962, p. vii). A decisive move in this direction is evident already in Kant's transcendental turn. "I entitle transcendental all knowledge which is occupied not so much with objects as with the mode of our knowledge of objects insofar as this ... is to be possible a priori" (1929, p. 59). This signals not merely a shift in epistemological focus but a fundamentally different ontological orientation, one in which phenomenological philosophy is inextricably implicated to 
the extent that "phenomenology ... is a transcendental philosophy" (Merleau-Ponty, 1962, p. vii). With Kant, the question of the essence of things shifts from what things are purely and simply in themselves, awaiting our submissive theoretical grasp, to the manner in which a priori things come to be for us, constituted as such within the realm of our experience. Here, all metaphysical talk of "things in themselves" gives way to talk of "objects" (literally, ob-jectare, "to be thrown against"), the essential inquiry into objects being an inquiry into "the experience in which alone, as given objects, they can be known" (Kant, 1929, p. 22). This signals too a shift in the question of truth. Transcendental philosophy is concerned not with the conformity of our essential knowledge to the essence of things in themselves, but with the a priori conformity of objects of experience to the very structures of possible knowledge. In this sense, "transcendental truth ... precedes all empirical truth and makes it possible" (p. 186). The question of ontology (i.e., of beings as beings) is posed on the same terms, that is, not as a matter of the actuality of things in themselves traced to their ground in necessary being, but of how things come to be for us originally in experience. From this perspective, the determination of essence still has priority in deciding the being of beings, yet essence now means the a priori "experiential" conditions of beings. The disclosure of these conditions is the disclosure of beings in their being. Hence, insofar as it treats of our understanding as it relates a priori to objects in general, transcendental philosophy is ontology ( $p$. 662 ).

Yet there is more to phenomenology's "putting essences back into existence" than is revealed by these abstruse theses. In Kant's terms, "experience" means "empirical knowledge" (e.g., 1929, pp. 162, 173), in other words, what in general as detached subjects we can come to know of objects of experience, and "essence" means the a priori conditions of the possibility of experience (cf. 1970, p. 3, n. 1), that is, what consciousness in general always already knows of such objects in virtue of the way it structures experience a priori. But precisely in maintaining an essential perspective on the lived human experience, phenomenology undercuts the primacy of empirical knowledge in this sense and the deployment of the world as a field of objects for a knowing subject. The "existence" back into which phenomenology puts essences is in the first place embodied and pragmatic existence, that is, our active engagement with things in a world disclosed first and foremost as a context of action. Phenomenologically, it is this engagement that has priority, in relation to which empirical knowledge is a founded mode of awareness. It is for this reason that phenomenology has been called, broadly speaking, a "praxis philosophy" in that it makes theory of action primary, preceding and grounding all theory of knowledge (cf. Ihde, 1979, p. xv). But this means too that it must consider all questions of essence in the same way. In other words, in contrast both to dogmatic metaphysics which presumes a purely theoretical essential insight outside the bounds of all possible experience and to 


\section{University of Alberta}

contemporary skepticisms (e.g., deconstruction) which dismantle all essential inquiry, phenomenology must consider essences as they are first constituted in lived experience as a whole, prior to all reflective dichotomies, general ideas and static forms posited by philosophy.

Discovery of essence [Wesen] (verbal): the original expression of being, which is neither object-being nor subject-being, neither essence nor existence: that which essences [west] (the being-rose of the rose, the beingsociety of society, the being-history of history) answers the question "what" as well as the question "that." It is not society, rose viewed by a subject, nor is it a being for itself of society and rose.... It is the roseness that extends itself throughout the rose.... Moreover, this roseness gives rise to a "general idea," which is to say, that there would be several roses, and one species rose, which is not indifferent but which results from the being-rose considered in all its implications. (Merleau-Ponty, 1964a, p. 228)

Now, "in withdrawing all generality from the first definition of Wesen" (p. 228), phenomenology might be said on traditional terms to have historicized essence. In truth, the reverse is the case. Phenomenology essentializes history, locating the constitution of essence in the whole way in which a matter intelligibly "holds sway, administers itself, develops and decays" in the course of experience (Heidegger, 1977b, p. 30 ). In this sense, essence is not first an abstract and "indifferent" universal under which falls all real and possible beings of a kind. Rather, essence is what endures in time as a rememberable continuity of sense, that is, as a history or motif, in virtue of which the presence of the thing as such is granted in our experience. Accordingly, the question concerning "what" something is as such leads to the question of what makes possible, before all predications, its presence in experience, and from there to the question of the ongoing context of meaning in virtue of which any being is disclosed as such. In this, the determination of essence is not captured in a final claim or result, as if, after all, the essence of essence were simply a fixed "what." It lies instead in the integral meaning revealed through the whole process of questioning, wherein all the ways in which essence is constituted are methodically recalled and mapped out. At the same time, the path traced by this questioning corresponds to, and is inseparable from, a path of questioning that traces the manifold ways in which the meaning of truth holds sway. In this correlation, "the true comes to pass ... only where the thing in question is uncovered in its essence" (p. 6); and a thing is uncovered in its essence only where it is disclosed in the full measure of its truth.

On this interpretation, a commonplace of lived experience, namely, that multiple things generically the same, or one and the same thing at different times and places, can seem "essentially" different, now becomes phenomenologically intelligible. To traditional philosophy, such talk is an oxymoron, for what is essentially different cannot properly be referred to as one. Yet consider that a statue of Apollo situated in a temple in 5th-century Athens, centering and revealing a whole Gestalt of lived 
meaning (of sacrifice, observance, and consecration), this Gestalt in turn holding the statue in advance within its place and being responsible above all for its coming to presence there as such, is an essentially different being than materially the same object installed in a contemporary gallery, held up as an object for aesthetic appreciation and as an example of human expression, catalogued and marketed by the culture industry, and confined to its place by the prevailing technological outlook. Of course, one might say that this statue is essentially the same because, for instance, it retains its specific integrity as a stone sculpture, or to be more "scientific," because it is molecularly unaltered, and hence that these different meanings in our experience are just a subjective coloring. But this is to forget that there is no sculpture encounterable at all within experience separate from these meanings, upon which then all "objective" determinations are founded as specific abstractions and further mediations.

In most respects, this concern for "essence" has the character of an intramural philosophers' puzzle. There is one respect, however, in which its existential import is brought home, and in which the interpretation I have been outlining is especially problematic. It concerns the manner in which the phenomenological determination of essence can serve as an appropriate measure or template to judge existential matters. It was precisely the need for such measures that, amid the conflicting voices of the time, sparked Plato's search for eide (1961, pp. 1574-1576). And it is the need for appropriate measure that, amid self-aggrandizing theories and conflicting practices, now challenges our pedagogical thinking. Of course, to those unshakably committed to eternal verities and essences, the phenomenological essentializing of history looks in the extreme like a virtual apocalypse, and its chief spokesperson, Heidegger, like a virtual Antichrist, (to be defeated, one assumes, in a Platonic second coming [cf. Bloom, 1988]). Notwithstanding this hysteria (well fueled by the recent revival of l'affaire Heidegger), there are philosophical reasons to be careful.

To counteract the uncanny and leveling indifference that prevails within the technological outlook, Heidegger quotes with approval a passage from Rilke's letters:

A house as the Americans understand it, an American apple or winestock from over there, have nothing in common with the house, the fruit, the grape into which the hope and thoughtfulness of our forefathers had entered. (1950, p. 268; Rilke's emphasis).

Heidegger invokes Rilke here to reawaken us to a sense of what it means to dwell, that is, to be truly at home, and is emphasizing the importance in this of a fundamental "rootedness" (Bodenständigkeit) established over time through the full range of our building and thinking (cf. Burch 1986). Yet the danger is clear: Without "essential" criteria that are strictly universal and grounded in universal reason, this effort risks 


\section{University of Alberta}

collapse into narrow-minded and obstinate parochialism, if not something worse. Thus, to extend an earlier trope (Burch, 1989), if all phenomenology is "inscription," what prevents it from "underwriting" all of the idiosyncrasies, bêtises, and bigotries of local practice and convention, or rather, by what essential standard can it reject these? Phenomenology offers us nothing in the way of "ideas" or "natures" by which to judge matters with veritable certainty. Yet it does disclose a measure.

To embrace a "thing" or "person" in its essence, that means: to love it: to favour it. Thought more originally, this favouring [Mögen] signifies: to grant essence. Such favouring is the proper essence of enabling [Vermögen] which cannot only accomplish this or that, but can let something "occur essentially" in its provenance [in seiner Her-kunft 'wesen'], that is, to let it be. (Heidegger, 1967, p. 148)

In this account, two aspects are held in balance. On the one hand, all talk of "letting be" is intelligible only on the assumption that beings are what they are in themselves and have a certain intrinsic integrity, that is, that they are something to be disclosed, embraced, let be or not. On the other hand, one cannot speak in the same breath of "granting essence" or "enabling," except insofar as the presence of these beings, and hence their "essential" occurrence, has conditions outside of the beings themselves. All elucidation of essence, and hence all standard of judgment, must be attentive both to the integrity of the beings in themselves and to the disclosure of meaning that allows them to be manifest. There is such an integrity, but it is accessible and thinkable at all only from within a hermeneutic situation. This situation is "originative," that is, it grants essence, but it is not something human beings willfully invent. Phenomenological thinking moves inescapably within this correlation. The intrinsic theoretical demands of phenomenology thus require that we seek in the midst of history to disclose our situation in the most comprehensive and radical way. However precarious and incomplete such a venture remains, it does not leave unquestioned and untransformed the prevailing temperament and point of view. Moreover, in the course of such reflection, it must take account of all of the things, both ontological and ontic, to which we are "indebted" (the full sense of Schuld in Heidegger's Being and Time) for our human being. The phenomenological task, then, is not only to take the full measure of our situation and the possibilities it proffers, but to consider within that horizon the ontic relations and conditions which too sustain human being. This does not mean that we fix things once and for all in a categorial scheme, or posit a Platonic "heaven" of transcendent forms. But it does mean to be attentive to what can be discerned in beings themselves and their interconnections as these bear upon what earlier was to referred to as our "insistent/existent" being (Burch, 1989). And although this can never take place outside of the horizons of our hermeneutic situation, what is sought are not simply broad ontological, interpretive conditions, but ontic dimensions as well. For, as an inscription of meaning, phenomenology not only writes upon a 
pretheoretical existential understanding, but also upon beings themselves within our understanding. And as philosophical, it seeks to discern by this writing not only the full measure of where we stand now, but needs and capabilities that belong enduringly to the possibility of being human.

\section{To the Things Themselves}

Phenomenology is directed essentially "to the things themselves." Yet it would be an odd inquiry indeed that did not make such a claim for itself. For, on the face of it, what this maxim enjoins is that we set aside all spurious, trivial, artificial, undemonstrated ways of thinking and attend to what is essential. But this expresses "the underlying principle of any scientific knowledge whatsoever" (Heidegger, 1977a, p. 28). Insofar as it presumes to be radical theorizing, the meaning and ground of the phenomenological call to the things themselves cannot be separated from what phenomenology itself demonstrates to be essential. ${ }^{3}$ And insofar as it presumes to be "first philosophy," what it demonstrates to be essential will turn on the question of "being." Without attempting to retrace all of our steps, we can see in broad sweep what this involves. Phenomenology's specific call to the things themselves is based on the primacy of lived experience. Yet it is not a call to return to lived experience simply as it is lived, since that is something we can never leave, however inured or distracted we may become. It is rather a call to investigate the intelligibility of lived experience, insofar as lived experience is the primary locus for the generation of meaning. In this respect, phenomenology characterizes lived experience essentially as being-in-the-world. The "world" in this sense is the original context of integral meaning presupposed in "anything we can designate," encounter or have access to "as 'being' (seiend)" (p. 6). It is in other words that "on the basis of which" (woraufin) beings are always already understood as such and accessible in the first place. But, as we have seen, this is just what phenomenology means by "being." Our being-in-the-world is the essential place of being itself.

To some, this invocation of "being" might well look like a philosopher's ploy, a partisan attempt to recolonize the territory and bring the native pedagogues and human scientists back in line. There are, after all, even among philosophers, other seemingly less esoteric ways to broach the issue of the "things themselves" and to bring them phenomenologically into view. In the second volume of her memoirs, Simone de Beauvoir (1960) recalls an evening from the early 1930 s at a Montparnasse café with Sartre and Raymond Aron. Aron had just returned from Berlin, where, while preparing his history thesis, he had also been studying Husserl. "We ordered the speciality of the house," she writes,

apricot cocktails. Aron pointed to his glass: "You see, my friend, if you are a phenomenologist, you can talk about this cocktail and make philosophy out of it!" Sartre almost paled with emotion at this; it was exactly what for 


\section{University of Alberta}

years he had longed to achieve-to speak of objects just as he saw and touched them and to extract philosophy from the process. (p. 141).

Notwithstanding Sartre's enthusiasm, or perhaps because of it, a cynic might find in this anecdote a confirmation of her wryest suspicions. For the image that it tries to make philosophy out of cocktails is just the sort of thing that tends to give phenomenology a bad name. Even Aron, it seems, had his doubts about where this orientation would lead (cf. Aron, 1975 , p. xi). Still, for phenomenology, Sartre's quest is at least in principle a valid one. In the essential turn to lived experience, phenomenology is obliged to consider the "original" presence of things to us, and by theoretical means to "recover" this presence in its truth (i.e., to give the "logos" of "phenomena"). And since the measure of such theorizing is the meaning of lived experience itself, it is obliged to begin by speaking of things just as they are "seen" and "touched." When we do this, however, two issues come immediately to the fore.

In the original presence of objects within experience, as $a$ dimension of their being "objects," there is for us a fundamental sense of their "otherness." In varying degrees, this sense is implicit always in all experiential engagement with things-in objects being put to use or resisting us, in their surrounding us, getting in the way, attracting, sustaining or repulsing us, in our navigating among them, in our touching and being touched by them. The experience of this "otherness" is perfectly familiar. It belongs in general to our basic "perceptual faith," the "deep-seated set of mute 'opinions' implicated in our lives" that on the whole "we see the things themselves, the world is what we see" (Merleau-Ponty, 1964a, p. 7). Implicit in this faith is the realization that prior to our conscious life things are already there to be encountered and that in themselves they have a reality and "insurmountable density" that is the terminus of our touch and gaze (pp. 5ff.). Such experience suggests to philosophy that things are "what and how they are" independently of the manifold ways in which we come to encounter, explain, or interpret them (cf. Heidegger, 1978 , p. 194), and hence beyond what we think and say, that they have their own independent "histories," actualities, and potentials (cf. Langan, 1984). But more than this may be suggested by experience. For, in the encounter with objects, there can at times be an almost visceral sense of their "otherness," the experience of an indefinable core beyond our language and thought.

And then, all of a sudden, there it was, clear as day: existence had suddenly unveiled itself. It had lost the harmless look of an abstract category: it was the very paste of things, this root was kneaded into existence. Or rather the root, the park gates, the bench, the sparse grass, all had vanished: the diversity of things, their individuality, were only an appearance a veneer.... de trop: it was the only relationship I could establish between these trees, these gates, these stones. (Sartre, 1938, pp. 180-181) 
Though he gives it vivid expression, there is nothing especially new about the philosophical point Sartre is making. A version of it has been long familiar from materialist attacks on idealism. "The reality of the sensuous, particular being is for us a truth sealed with our blood.... To sensuous consciousness it is precisely language that is unreal" (Feuerbach, 1959, p 185). Made against Hegel, Feuerbach's objection is that what we say about things does not capture their essential truth, that is, the personal, visceral character of their presence in experience, replacing the thing itself with the constructs of language. In one respect, this point is well taken. Were it the case that language served simply as a "veneer" of general thoughts over the sensuous reality of experience-over feelings, passions, sensations, as well as the brute factuality of things-then it would be suspect. But the issue itself is more complex. On the one hand, it is undeniable that sensations are felt by sensate beings independently of language and meaning. But, as we have seen, sensations enter into lived experience when, as it were, something is made of them, that is, when they have become meaningful and are situated in terms of other meanings (cf. Danner, 1986). For example, a painful sensation can be felt, but an experience of pain is always a pain of something, or from something, or in something, or a sign of something, that is, it is always situated and read. Similarly, for the whole class of voluntary acts (e.g., decisions, promises, wishes) and emotions (e.g., reverence, guilt, wonder), experience is not prior to, but presupposes and is a function of contexts of meanings. I will this or that, I am possessed of this or that emotion, not first because I am sentient, but because I exist in a world of transcendent meanings. On the other hand, the experience I have in virtue of language/meaning is an experience of things, not just of language. There is something "to be experienced" that is revealed in experience as transcending the act that brings it to be. Yet this does not entail that there is in experience an original "stuff" over which meaning is placed as veil on truth. From the start, everything encountered in lived experience is a meaning, and what is manifest in meaning is simply further meaning. Things in themselves are either wholly within the meaning of lived experience or they are quite simply nothing.

Just as phenomenology must consider objects of experience in terms of a context of transcendent meaning, so too must it consider "subjects." By "phenomenological" we mean "the understanding of an event from the perspective of the participant" (Barritt, et. al., 1983, p. 140). We turn to phenomenology "in order to describe "what happens in the mind of the individual actor"' (Barber, 1989, p. 218). Such statements are familiar in the local discourse. Yet, when my erstwhile colleague caricatured phenomenology (Burch, 1989), it was the "scientific" possibility of just such understanding and description that she sought to lampoon. In her view, the attempt to describe objectively our own subjective experiences, let alone those of another, was a "hopeless" task. Even though her caricature did not have the force of a conclusive argument, we would do well 


\section{University of Alberta}

not to dismiss her charge of subjectivism out of hand, since its represents a widespread view of phenomenology, a view that is deeply problematic.

If one seeks to discover a "subject" at a visceral level, among the personal feelings, sensations, affections that permeate lived experience, the risk of subjectivism is most imminent. For there is an obvious sense in which these dimensions of lived experience are purely private and not accessible to others. I am directly attuned to my own sensations, feelings, and affections precisely because they are mine, but I cannot experience directly another's experience, and have only an oblique and uncertain inferential access to their sensations, feelings, affections. Thus, for example, no amount of phenomenological attentiveness can bring me to "know" what the pain of childbirth is like, if the focus of this knowing is meant to be the feeling itself. That feeling I can know only if I too have had such pain, or presume to guess at what it must feel like from some analogous experience of my own, and in no case can I "know" its particular intensity for someone else. Yet, even at this visceral level, phenomenological analysis already shows the way to undercut subjectivism and the egocentric predicament. For it shows that sensations, feelings, affections are not primary elements within lived experience but come to be as such only as they are situated within contexts of meaning. By virtue of its physiology, a creature with a central nervous system will suffer pain under specific conditions regardless. But in order for that pain to be a part of the creature's lived experience, and thus for it not to disappear into an oblivion of disordered passing sensations, it must be interpreted and integrated into the unity of one's conscious life. Accordingly, when phenomenology asks, for example, what childbirth pain is "like," it is the meaning of that pain that is in focus, a meaning in virtue of which the pain is constituted in the birthing mother's lived experience (cf. Bergum, 1989 , chap. 5). Not being a woman, I can never presume to know or appreciate the full dimensions of that meaning. But $I$ can have an adequate sense of it; for unlike the sensation itself, the meaning is not purely and simply private.

Phenomenology also risks subjectivism when it considers its task to be the "reproduction" of the conscious projects and purposes of others. Although at this level it is explicitly meanings (and not mere sensations) that are in question, the difficulty has a form analogous to the previous case. I do not know directly the intentions of others but can only conjecture as to what these are from what others say and do. And my conjectures reproduce these meanings not in themselves but ever only from my own perspective.

Constituted as it is within the unique stream of consciousness of each individual, "intended meaning" is essentially inaccessible to every other individual... We are asserting neither that your lived experiences remain inaccessible to me nor that they are meaningless to me. Rather, the point is that the meaning I give to your experiences cannot be precisely the same meaning you give to them. (Schutz, 1967, p. 99) 
Now, strictly at the level of these express intentions and purposes, it would be dubious to claim that we understand someone better than she understands herself. "It is enough to say that we understand in a different way, if we understand at all" (Gadamer, 1975, p. 264). Two things are involved here. First, my rendering of another's experience, however trusting and faithful I presume to be to what she says and does, is always inevitably $m y$ rendering, that is, a story constructed within the stream of my experience and personal history and hence meaningful to me in a way always different from the meaning of the experience to the participant. Second, it is not that my understanding is inevitably blinkered by my limited perspective, but that my perspective with all of its prejudices, is the very condition of my understanding, its locus and medium.

Ironically, this entire issue of subjectivism constitutes a decisive impasse for phenomenology only insofar as, and against its avowed purposes, phenomenology stops short of "true beginnings" and takes its directive instead from "philosophies" (Husserl, 1965, p. 146), locating the origin of the self in some version of the cogito ergo sum posited by Cartesian radicalism. The difficulties which the Cartesian project faces in this regard have already been adumbrated. It must construct an epistemological bridge from the self-certain subject, the solus ipse, to the reality and truth of objective being and so overcome an originally posited solipsism; and according to the grounding principle of its methodology, it must also attempt this construction to the same exacting standard of knowledge with which self-consciousness is immediately certain of its own existence. The subjectivist dilemma in this is clear. Though I can have an immediate reflective access (whether true or not) to my own feelings and intentions and an immediate reflective certainty of my own existence as thinking, I have only an inferential knowledge based on my observations of overt behavior of either the existence or the inner life of other selves. "Hence I can never know, and certainly never know immediately, that I am not radically alone" (Fackenheim, 1967, p. 240). Now, were phenomenology nothing more that a variation on Cartesianism, it too would be beset by these difficulties. To that degree as well, the concerns expressed in my colleague's caricature would be apposite, if not definitive. In the light of what I have already argued on this issue, such concerns would not seem to have much force. Yet no less a person than Husserl himself characterizes phenomenology as "neo-Cartesianism" and goes to great lengths to defect the charge of solipsism (1970a). This alone should give us pause and obliges us to consider the issue of subjectivism more thoroughly.

Yet, even with Husserl, the exact character and degree of phenomenology's Cartesianism is not easily determined. "Precisely by its radical development of Cartesian motifs," Husserl claims, "phenomenology is obliged to reject nearly all the well-known doctrinal content of the Cartesian philosophy" (1970a, p. 1), in particular, Descartes' ready identification of the ego cogito as res (substantia) cogitans. 


\section{University of Alberta}

By no means must phenomenology accept as a matter of course that, with our apodictic pure ego, we have rescued a little tag-end of the world, as the sole unquestionable part of it for the philosophizing Ego, and that now the problem is to infer the rest of the world by rightly conducted arguments, according to principles innate in the ego. $(1985$, p. 24)

Neither a concrete self in the world nor an indubitable item of the "ultimate furniture of the universe," the ego uncovered by radical reflections is for Husserl the absolute transcendental limit to the world, the unsurpassable subjective ground of all that which can come to be for us, and hence the being of all beings. So basic is this doctrinal difference, however, that it suggests an even deeper rift between Husserl's phenomenology and its Cartesian progenitor on the issue of radicalism itself (cf. e.g., Kockelmans, 1967, pp. 72-76). There is no question that for Husserl the phenomenology of consciousness returns to the ego cogito as its radical point of departure. But at the same time by disclosing in this return the full compass of consciousness' essential "intentionality," Husserl insists that phenomenology escapes the trap of solipsism at its source (cf. Burch, 1990, pp. 137-140). Unlike Cartesian subjectivism, Husserl's phenomenology is not based expressly on the pure interiority of the self-conscious ego but on the consciousness of the world taken strictly as one's - the transcendental ego's-phenomena. This marks a crucial difference in orientaion. On the Cartesian model, the reality and truth of objective being, including that of other selves, lie originally outside the essential structure of consciousness understood as "representation" (i.e., as the subject's positing and securing of cogitationes in self-certainty), and so against the presumed errors and uncertainties of everyday experience, philosophy must attempt to "recreate" this reality and truth on an absolute philosophical foundation. With the phenomenology of consciousness, in contrast, the reality and truth of objective being are in principle implicated originally in the essential structure of consciousness as "intentional" (i.e., as "bear[ing] within itself, in a manner peculiar to the meant, its particular cogitatum" [Husserl, 1970a, p. 33]), and so have only to be explicated more originally. By means of such explication, then, the human beings that exist for one in everyday lived experience are not, as it were, made to disappear, as they are in Cartesian doubt. Rather they are "transformed" into "alter egos ... having the ontic meaning of implicata of my original intentional life" (Husserl, 1970b, p. 258). Moreover, as such "implicata," these "alter egos" are not simply a particular, possible achievement of intentional life but an intrinsic, essential dimension of it. "Within the vitally flowing intentionality in which the life of an ego-subject consists, every other ego is intentionally implied in advance" (Husserl, 1970b, p. 255; italics added), "implied" of course not as real particular persons in the flesh but as others in general, that is, as a "transcendental intersubjectivity" that precedes and makes possible all relations to actual others. To this difference in orientation belongs also a corresponding difference in the basic sense of the philosophical inquiry. Whereas on the Cartesian model the guiding question in regard to the 


\section{0th Anniversary of the Faculty of Education}

other takes the form, "Is genuine knowledge of the existence and nature of other selves possible?", this being part of the broader epistemological query, "What can I know?", the guiding question for a phenomenology of consciousness is, "There is knowledge of others; how is it possible?", the fact of this original knowledge being the very condition of our ability to speak of mistake, illusion or falsity with respect to others in the first place (cf. Merleau-Ponty, 1964a, p. 19). To be sure, on these terms the phenomenology of consciousness faces its own difficulties. It must show how in the intentional life of the transcendental ego not only a "monadic plurality" of other selves as such is constituted a priori but also (and more to the point) how at the same time this plurality is constituted as a singular "monadic community" to which both self and other belongs essentially, ${ }^{4}$ a "community" intrinsic to each ego-subject's constitution of the world as such, at once both "transcendental" and "intersubjective" (cf. Husserl, 1970a, pp. 139-141). Such phenomenology must also show how this transcendental intersubjectivity as a "pure, intentional, mutual internality" (Husserl, 1970b, p. 255) is indeed able to make possible in both its everyday mutual externality and its communion the concrete world of mundane interpersonal lived experience. However daunting these requirements may be, they are not precisely the concerns of Cartesian subjectivism. The challenge they pose is not to plot an escape from an invented subjectivist prison, but to explore a transcendence to others that is coeval with the very selfhood of the self and which is the prior ground of all particular instances of actual communication, as well as its failure and breakdown. It is the exploration of this transcendence which in principle distinguishes all radical phenomenology from Cartesianism.

In the final analysis, however, Husserl persists in the attempt to account for this original transcendence in essentially Cartesian terms, that is, in terms of the primacy of the self-given ego cogito. "First of all, before everything else conceivable, $I \mathrm{am}$. This ' $\mathrm{I}$ am' is for me, the subject who says it, and says it in the right sense, the primitive intentional basis for my world." (Husserl, 1969, p. 237). It is the intentionality of the selfgiven ego which for Husserl accounts for all transcendence whatsoever. "Transcendence in every form," he claims, "is an immanent characteristic, constituted within the ego. Every imaginable sense, every imaginable being, whether the latter is called immanent or transcendent, falls within the domain of transcendental subjectivity" (1970a, pp. 83-84; italics added). What is claimed here of transcendence in general, if granted, would hold pari passu for the transcendence to others. Not only does "the ego who says, with the universality in question here, ego cogito ... include in his actual and possible cogitata everything actual and possible for him. ... "but also" in this ego, every other ego receives sense and acceptance as an other ego" (Husserl, 1969, p. 237). To be sure, this original ego-absolutely unique and self-given - does not constitute the other as a mere lifeless thing but as an other ego who would likewise constitute its world as I do mine and so would constitute me as I do it. 


\section{University of Alberta}

Nevertheless, the basic tenet and starting point remains the same: the unique, absolute self-given "I" constitutes the other, just as well as everything else.

That this account of intersubjectivity poses arcane problems, scarcely anyone would deny. Even a Husserl epigone like Schutz (1975) depairs of tracing successfully the convoluted set of intentional relations that would have to be involved. Yet, as a consequence, Schutz gives up on the transcendental dimension of the issue and takes "intersubjectivity" simply as "a datum (Gegebenheit) of the life world" (p. 82). But the short-coming of Husserl's account (and indeed of all phenomenology of consciousness) is not its lack of phenomenological subtlety, nor even its attempt to cast the question of intersubjectivity in transcendental terms. It is rather that it fails to pose radically enough the question of the essential origin of the self as ego cogito, taking the "I am" as a first principle instead of the site for a more original exploration. Without presuming to carry out such an exploration here, enough of its highlights can be traced to show the true place of phenomenology before all subjectivist traps.

In their essential origin, before every possible ego cogito, constitutive act or intentional correlation, that is, before the subjectivity of the subject and whatever then a subject can posit or designate, self and other are equiprimordially. This equiprimordiality has two dimensions, corresponding to the ontological difference between being and beings (cf. Burch, 1990, pp. 139-140). First, individual selfhood is not given absolutely before the world but comes to be in actual relations with other incipient or already actual selves. Second, such actual relations have their ground in an original mutuality always already in play, a world of meaning that is the prior situating context of actual encounters and the ground of any ostensive reference, whether objectively or subjectively valid. In one sense, these two dimensions of selfhood and subjectivity are coessential and thus mutually dependent. At one and the same time, there is selfhood only in virtue of actual encounters, which are themselves possible only on the basis of a prior mutuality, and there is selfhood only in virtue of a prior mutuality, which is first realized only in actual encounters. Though interdependent, these dimensions are also asymmetrical. For, ultimately, the mutuality of a common world of meaning precedes and makes possible the actuality of self and other and their relations, not vice versa. ${ }^{5}$ This mutuality is the terminus ad quem of phenomenological radicalism in its pursuit of the origin of the self and the terminus a quo of phenomenological reflection in its pursuit of the essence and truth of the interpersonal.

The intelligibility of this view of selfhood depends on two theses not common in the mainstream of Western philosophy. The first, roughly put, is that the selfhood of the self lies in what it does, that its essential being as a self is consequent on its self-activity (cf. Burch, 1990, pp. 


\section{0th Anniversary of the Faculty of Education}

136-137). The second is that such self-activity is ultimately situated, and thus limited and enabled, by an englobing context of meaning, an "hermeneutic situation," that always already transcends as a whole any objective representation and establishment of beings in relation, and thus is more original and surpasses altogether the terms it relates (cf. Burch, 1990 , pp. 148-152). ${ }^{6}$ On this account, the realization of a common meaning in lived experience does not occur after the fact of selfhood as a particular, dubious accomplishment, but is an integral, fundamental dimension of the finite process in and through which each self in its own way realizes itself as such. To be sure, between what is common and what, literally speaking, is idiomatic in this process there is still a difference. On the one hand, because in each case it is one's own every such process of self realization "implies the possibility and necessity of the most radical individuation" (Heidegger, 1977a, p. 38). Yet it does not follow from this that the meaning realized in each process amounts simply to an idios kosmos, a purely private world. Rather, on the other hand, what in any individual case is actually realized privately, idiomatically as one's own meaning presupposes at its origin, since this is presupposed in the very origin of selfhood, a common world of possible meanings. These meanings constitute a "world" in the sense of an integral, englobing, and situating context of significance, which is the original, fundamental context of selfhood. Moreover, as appropriated in and to one's very selfhood, this "world" is "common" in the sense of "usual," "familiar," "customary," even if for that very reason it is not as a rule truly known. In having this original, essential relation to selfhood, this world is also the existential/ontological basis for all that which a self can perceive and designate within the course of its own lived experience, that is, for the common things of its everyday life, as well as for whatever objects it can point out publicly and so have in common with others. Moreover, this world is a world of "possibilities" of meaning not as the given potentials of an entity to be actualized, nor as terms of a merely imagined, logically coherent scenario, but in the original sense of what, before all explicit actualizations, enables the self as self-constituting, "preserving it in its essence and maintaining it in its element" (Heidegger, 1967, p. 148). In realizing itself in relation to this world, the self performs a twofold dialectical movement, one which parallels at a more original level the dialectical movement of phenomenological reflection (cf. Burch, 1989, p. 196). ${ }^{7}$ The meaning it realizes is not actual before its choice of self and comes to be actual in that choice, otherwise the self would be a mere product and in that respect not a self at all; the meaning the self realizes must in some sense "be" before the choice of self, otherwise there would be no choice but an absolute self-creation. Here, again, the priority of possibility over actuality holds sway (cf. Burch 1989, pp. 198-199). The ever latent meaning of the world, the tacit intelligibility that is the truth of lived experience, is existentially/ontologically prior to whatever meanings a self can or does realize in realizing itself and is the basis of all intersubjective relations. 


\section{University of Alberta}

In each case, then, there belongs to the self's hermeneutic situation and hence to its very selfhood an original "common sense," not as a universal unadulterated natural knowledge for all humans, but as a "cultural system" (Geertz, 1983, p. 75), the familiar everyday local meanings "that found communality" (Gadamer, 1975, p. 21). It is precisely because in its very being the self is always already implicated in some such common sense that there is as a rule no need for phenomenology (or any other discipline) to reconstruct the conscious intentions and purposes of others, nor to retrace an original empathetic relation that would bind separate selves.

Automatic and impersonal, significant without intending to signify, ordinary practices lend themselves to an understanding no less automatic and impersonal: the picking up of the objective intention they express in no way implies "reactivation" of the "lived" intention of the agent who performs them. The deciphering of the objective intention of actions and works has nothing to do with the "reproduction" (Nachbildung, as the early Dilthey put it) of lived experiences and the reconstitution, unnecessary and uncertain, of the personal "singularities" of an "intention" which is not their true origin. (Bourdieu, 1977, p. 80)

Typically, we succeed very well in understanding what someone else intends, (and indeed we first come to have singular intentions of our own), not through complex calculations and chains of inference that lead out into the world from the pure reflexivity of our ego, but more or less directly in virtue of our original and habitual participation as selves in a shared world. This is not to deny that we do at times and at different levels explicitly calculate and contend with the intentions and purposes of others, which, moreover, in their singularity are ultimately concealed to us, except as they are expressed and interpreted in what others say and do. But all such express problems and their resolution arise and get worked out against the essential background of some shared world always already in play in our selfhood. To be sure, there are also occasions in our relations to others when, beyond such problems and their resolution, the shared world itself can come more or less directly into question, for example, when the world and hence the selfhood of the other is still more or less inchoate; when the idiomatic dimensions of the other's world occlude or oppose the communal in such a way as to block everyday communication and even to threaten the integrity of the afflicted self in its essential being in the world; when the world of the other amounts to a fundamentally different "common sense" and so in truth is alien to us, not properly our own world. This questionableness is reflected in the various disciplined procedures that presume to determine and order the intentions and purposes of others, for example, in political analysis and original historiography where the actions at issue belong to a world which, in virtue of its common sense, is contemporaneous and so as a rule is both intimately familiar yet concealed; in reflective historiography where the actions at issue belong to a world more or less remote in time from our own, a world which must be recovered if the actions are to be 
reenacted in thought by the historian; in ethnography where our participation in a community is chosen and ulterior, and hence our understanding is inevitably non-native; in psychopathology where, in the wake of the breakdown of the self, communication and communal participation have to be reconstructed and so a common sense reestablished; in pedagogy where communication and communal participation must be facilitated as a developing self is initiated into a world. The principle aim of phenomenology and its chief contribution to all such ventures is not to recover subjective expressions and intentions, but to disclose and explicate the underlying intelligibility of lived experience. It is not the individual psychological subject, but a truth which precedes and makes possible anything subjective or objective, that phenomenology truly seeks. Because of its intepretive distance, phenomenology can show us dimensions of the hermeneutic situation and its "common sense" concealed to those who actively share it. Indeed, in this disclosure lies its pedagogical value. But phenomenology does not put us inside another's head. In this respect, its task is to disclose the truth of selfhood, not to engage a particular self. ${ }^{8}$

These issues are brought into focus in a way especially relevant to the concerns of "phenomenology and pedagogy" through a "working note" by Merleau-Ponty (1964a) entitled the "problem of analysis."

Do we have the right to comprehend the time, the tempo (vitesse) of the child as an undifferentiation of our time, of our space, etc.? This is to forge (rebattre) the experience of the child upon our own experience, at the very moment when one is trying to respect the phenomena. For it is to think that experience as the negation of our differentiations. It would be necessary to go as far as thinking it positively, as far as phenomenology. (p. 256).

This passage warns of a familiar stumbling block in the domain of phenomenology and pedagogy. For "as long as we see the actions of little children through the models of our shared adult conventionality, we are not likely to see the world as children, in their own uniqueness, see it" (Beekman, 1983, p. 40). Instead we "play the fool in a mirror cabinet, always reflecting our own sights" (Meyer-Drawe, 1986, p. 50). Although he raises this issue in terms of children, Merleau-Ponty gives it a broader scope. The question of a "positive" understanding is not limited to our relations with children, but "arises in regard to all others," even in that intimate relation when, in reflection, one becomes "other" for oneself (Merleau-Ponty, 1964a, p. 257). Moreover, to think this issue "as far as phenomenology" does not mean to recover straightway the expressions and intentions of the other by setting aside our prejudices. Rather, it is first to uncover the essence of otherness itself, including that of the child and of myself in reflection, "archeologically," that is, in terms of their very origin.

This is the real meaning of Merleau-Ponty's proposed "solution." 


\section{University of Alberta}

to recapture (ressaisir) the child, the alter ego, the unreflected in myself by a lateral, pre-analytic participation.... When I perceive the child, he is given precisely in a certain divergence [écart] (originative presentation of the unpresentable) and the same for the perceptual lived experience of myself, and the same for my alter ego, and the same for the pre-analytic thing. Here is the common tissue of which we are made. The wild being.... The essential: to describe the vertical or wild being as that pre-spiritual milieu without which nothing is thinkable, not even spirit, and by which we pass into one another, and ourselves in order to have our own time. It is philosophy alone that gives it. (1964a, p. 257).

Although couched in elusive terms, the sense of this "solution" is reasonably clear. The phenomenological task is to recover "a pre-intentional present" (p. 261) that underlies all subject/object relations, all explicit differentiation and otherness. It seeks a "perception," which only philosophy can grant thematically, of "wild or vertical being," the "brute fabric of meaning" that is woven through all levels of experience, preceding and making possible all particular horizons and accomplishments. The perception does not "recapture" the child per se, nor anyone at all in particular. Rather, it recovers the "unreflected in myself" in its universal validity. As Merleau-Ponty terms it, this "unreflected" is "wild being," the silent and invisible ontological fond out of which self, others, and things arise in reciprocal relations. What is first disclosed phenomenologically is not what differentiates us at the level of express meanings, but the pre-intentional "common tissue" that is the "same" for all. We understand others phenomenologically not purely and simply in themselves but as "divergences" from this commonality.

In its specifics, however, this "solution" poses difficulties (cf. Burch, 1985). It delves down into the juxtaposition of individual selves in lived experience to disclose the implicit essential dimension that makes the being of selves-in-relation possible in the first place. Yet, in the very name of universality and radicalness, it points to an ontological source so "wild" that it seems to lie outside the meanings intelligible within anyone's actual lived experience and thus prior to selfhood. But this brings us back directly to the question of "being" we thought we might avoid. Though it does not "iterate what is given and understood in lived experience in the way that it is given and understood" (Burch, 1989, p. $192)$, neither can phenomenology simply invoke an ontological source, no matter what its explanatory coherence, not already in some way intelligible individually within lived experience itself. Given what we have thus far seen of the essential determination of lived experience, that source must hold sway existentially and individually, rather than generically. The issue, then, is not one of "divergences" in a "common tissue," but the projection and appropriation of transcendent meanings as essential to the way a self constitutes itself. 


\section{A Methodological Conception}

In contemporary philosophical discussions, at least in those with epistemological preoccupations (which means in the mainstream of contemporary English-speaking philosophy), the prevailing concept of "method," and even the precedence of "method" itself, is Cartesian in origin (cf. Schouls, 1987). "By 'method", Descartes writes,

I mean reliable rules which are easy to apply, and such that if one follows them exactly, one will never take what is false to be true or fruitlessly expend one's mental efforts, but will gradually and constantly increase one's knowledge til one arrives at a true understanding of everything within one's capacity (1985, I, p. 16).

Method in this sense functions as both a negative and a positive condition of truth, that is, not only as a formal means to preclude error but as a concrete means to grasp what is true. In Descartes' account, moreover, method has in the domain of what is humanly knowable a universal application. "Human wisdom ... remains one and the same, however different the subjects to which it is applied, it being no more altered by them than sunlight is by the variety of things it shines on" (p. 9). By following the prescriptions and proscriptions of method in this sense, one can avoid being led astray by vagaries and incidental peculiarities seemingly imposed by a particular subject-matter under interrogation. Strict adherence to the rules of method should keep us everywhere and always on the right track.

To the extent that "phenomenology" signifies primarily a methodological conception, and we understand method in these Cartesian terms, it might well seem that those who turn to phenomenology with a practical intent can remain "impartial" regarding the philosophers' questions about "being" (cf. van Manen, 1989a, p. 250). After all, the phenomenologist most preoccupied with the "question of being" is the one who also claims that the expression "'phenomenology' does not characterize the 'what' of the objects of philosophical research in terms of their content [das sach haltige Was] but rather the 'how' of that research" (Heidegger, 1977 a, p. 27). Surely, then, one could apply the method without being committed to any specific philosophical aims or theses.

Yet this conclusion is precipitous, for it fails to consider the meaning and ground of method itself. Immediately after claiming that "phenomenology" denotes a method, Heidegger asserts: "The more genuinely a concept of method is worked out and the more comprehensively it determines the principles upon which a science is to be conducted, all the more primordially is it rooted in the way we come to terms with the subject matter itself [Sachen selbst], and the farther removed it is from what we call 'technical devices"' (1977a, p. 27). This suggests that the legitimation of a method cannot properly be given in advance in terms of an abstract and general standard of rigor, but must be decided essentially in relation to the subject matter in question (cf. Barritt, 1986). Now, 


\section{University of Alberta}

since the method is meant to insure genuine knowledge of the subject matter by keeping the investigation on track, it must be essentially appropriate to that subject matter in the first place and derive its authority from this relation. Accordingly, "in each kind of study, one ... searches for that degree of precision which the nature of the subject matter admits" (Aristotle, 1962, p. 5, my emphasis). At the same time, however, insofar as it does effectively guide investigation, a method cannot be a neutral set of procedures simply brought to the subject matter as it is in itself. For method is able to provide a directive to inquiry only because it already determines what in principle can be disclosed in the subject matter and thus what of that domain is really real. "Method ... decides in advance what truth we shall seek out in the things. [It] is not one piece of equipment of science among others but is the primary component out of which is first determined what can become an object and how it can become an object" (Heidegger, 1967, p. 102). Through its method, then, a science not only determines in advance how investigation must proceed in order to ensure rigor, but also what the essential constitution of the subject matter itself must be. Only that which accords in principle with the method can come under "scientific" scrutiny in the first place and thus be the subject matter in a strict sense. Accordingly, in our own methodological debates, the basic issue is not one of competing and incompatible procedures for investigating social reality as a given phenomenon, but of different prior interpretations of what is essential to that reality and hence of what in principle constitutes the subject matter. Where we explicitly disagree as to "how" the reality is properly to be investigated, we already tacitly disagree in fundamental way as to "what" the reality "truly" is. Accordingly, to the extent that our methodological differences get represented as procedural problems decidable in principle on abstract epistemological grounds extrinsic to the particular subject matter, the real ontological foundation of these differences is concealed. This in turn conceals the fact that it is at root not the legitimacy of "technical devices" but the essence of the subject matter that is in question. At this level, the separation of ontological and epistemological issues is a false one.

This account of method parallels our early discussion of the basic conundrum of phenomenology (Burch, 1989). On the one hand, if a method is to be legitimate, it must always already accord fundamentally with the subject matter in question. "Genuine method is based on viewing in advance and in an appropriate way the basic constitution of the 'object' to be disclosed, or the domain within which the object lies" (Heidegger, $1977 \mathrm{a}$, p. 303). Without this "preview" of the subject matter, method would be groundless. On the other hand, method must lead us beyond what is already known of the subject matter in an everyday way to disclose it in its truth. Without showing us the way to this transcendence, method would be superfluous. Yet the only knowledge one can have "in advance" of a subject matter is ontological knowledge, knowledge of 


\section{0th Anniversary of the Faculty of Education}

what always already pertains to the subject matter as such. "Thus any genuine methodological consideration - which is to be distinguished from empty discussions of technique-must ... give information about the mode of being of the entity that has been taken as a theme" (p. 303). Here, however, one must distinguish a certain "scientific conduct" (Verfahren) - the following of pre-set rules of inquiry to yield instrumental knowledge of entities, rules which themselves are in need of ontological grounding-from "thoughtful procedure" (Vorgehen)-the self-grounding course of radical inquiry into the truth of being (p. 445). Were phenomenology simply a technique of positive science, it could provide compelling credentials for its claims by following the rules of its method, rules whose appropriateness receive their ontological justification through a more fundamental inquiry. Yet, because it is radical thinking, phenomenology is methodologically self-defining and self-legitimating. Thus it establishes the justification for its procedure in and through the actual process of inquiry. But since it is this process itself that discloses the subject matter essentially, phenomenology can provide no compelling credentials to ensure that its claims agree with "reality" (cf. Heidegger, 1971, pp. 184-186). Whereas, in the positive sciences, the specific rules of rigorous inquiry are spelled out in advance, phenomenology admits of no such preliminaries or guarantees. In this respect, the attempt to spell out the steps of a "phenomenological method" (cf. Spiegelberg, 1982) is quite misleading. "Everything here is a way of responding that examines as it listens" (Heidegger, 1971, p. 186). Thus if one means by "method" an epistemically prior, unerring recipe that ensures compelling propositional results, then there is no phenomenological method. If, however, one understands the expression more literally as "following along a way" (i.e., meta ton hodon), then the method of phenomenology is nothing other than the path that phenomenological thinking itself tentatively inscribes in attempting to disclose the subject matter essentially.

As a method, phenomenology is caught in a familiar circle. Guideposts to phenomenological investigation are warranted only if they mark out an essential, inclusive dimension of lived experience; yet we can demonstrate that they do delineate such a dimension only through phenomenological investigation, which first discloses lived experience essentially. The procedure is warranted by the essence of the subject matter; the subject matter is disclosed essentially by the procedure. This sort of circle would be "vicious" were the conditions for working through it not already met implicitly in a prior existential understanding of lived experience (the "of" being both subjective and objective genitive); and it would be merely a "tolerated, though inevitable, imperfection" of phenomenology were the very possibility of phenomenological interpretation not rooted essentially in such understanding (Heidegger, 1977a, pp. 151-153, 31416). Still, for this very reason phenomenological inquiry is inescapably a "phantastic undertaking," not because it eludes "circularity" by a "fictitious arbitrary construction," but because it both rests essentially on a 


\section{University of Alberta}

prior existential understanding and yet must decide itself the "truth" of that understanding (p. 260). Yet, on these terms, no other warrant could be given for a methodological direction than what phenomenological inquiry is able to disclose within its own self-defined limits.

\section{Human Science Research}

Though in recent years "consequential shifts have occurred in the place and acceptability of human science research in the English-speaking world" (van Manen, 1989b, p. 1), on the prevailing conception of scientific research, there still seems something odd, if not contradictory, in the notion of human science research as a distinct form of "scientific" inquiry. What is troublesome is not that matters pertaining to human being can be delimited into definite areas of investigation, or that the investigation of each area can have its own specific research procedures. Indeed, the prevailing conception of scientific research does not merely allow but requires the demarcation of reality into definite areas of inquiry, each investigated by a particular science having its specific procedural techniques. What the prevailing conception does not permit, however, is that these divisions of investigative labor and province, along with the differences in individual procedures they entail, be radical distinctions. They are supposed instead to belong within an essential uniformity of method worked out in advance on independent epistemic grounds, constituting the shared scientificity of all genuine sciences and implying a corresponding essential uniformity to all of the reality that is scientifically investigable. On these terms, the seeming contradiction in human science research lies in its claim as a science to a unique methodological character based on a fundamentally distinctive disclosure of the domain of the human. Admittedly, on this point we might as human scientists be more guileful and in describing what we do simply use the phrase "science research" to allay the doubts of less sympathetic colleagues and to gain credibility with the relevant authorities. Yet the more inquisitorial are apt only to be made more suspicious by this label, demanding more detailed confessions of our scientific faith. Under their scrutiny, we would be expected either to situate human science research directly within the prevailing general conception of science (and so deny its distinctiveness) or to admit and renounce our heretical ways. Failing that, we risk excommunication. Of course, in good conscience we cannot do otherwise than to take our methodological stand more explicitly and self-critically, not only absolving ourselves from the methodological rule of scientific orthodoxy but also showing in positive terms where that leaves us. To that end, I propose first to explore the essence of scientific research on the prevailing conception in order to begin to draw the boundaries of human science research in the contrast. My intention is not to follow the internecine debates of the philosophers of science, which in any case take for granted the essence of method. Rather, I shall explore what is revealed about the character of scientific research as it governs our institutional practices in order to disclose its essential meaning more 
originally and inclusively and on these terms to begin to mark off from the domain of scientific orthodoxy the essential place of human science research.

On the prevailing conception of science, there is at root an effective identification of knowledge with the product of research. This is evident, for example, in the institutional division of our professional and professorial duties into "teaching and research," where ideally the latter is organized into discrete projects with well-defined aims, procedures, and results. As research, intellectual work in the university takes on the external characteristics appropriate to the production of knowledge in this form. More and more it becomes an activity organized in advance for the ready evaluation and support by vetting committees, governing bodies, and funding agencies, delimited in advance for the most expeditious attainment and presentation of usable results. It is work increasingly enabled by computers, test-marketed on the conference circuit, negotiated with publishers and editors, summarily processed, evaluated, used or discarded, and readily converted into degrees, promotions, and honors. Though they reflect how we do things, these characteristics are not simply the result of a particular, arbitrary organization of academic life. Rather, the transformation of knowing into research tends itself to elicit a particular sort of organization in the context of which intellectual work comes to have these characteristics.

It is not then just the circumstances in which intellectual work is presently carried out nor the form in which it is presented that is at issue. The transformation of knowing into research transforms the very meaning and legitimacy of such work. In principle, a project is legitimate to the extent that it is clearly researchable. What is researchable is something that has been delimited and made manageable in advance by being posited within a circumscribed sphere of objects. A new fact, correlation, or causal connection may be discovered within this sphere; but the essential boundaries of the sphere itself are predetermined by the manner in which it is methodologically disclosed.

With this transformation comes also a transformation of intellectual "questions" (i.e., those issues having indeterminate boundaries that engage us existentially and concern our being-in-the-world) into discrete problems that we posit and attack, to be solved once and for all.

A problem is something which I meet, which I find complete before me, to which I can therefore lay seige and reduce.... A genuine problem is subject to an appropriate technique, by the exercise of which it is defined in its problematic character.

(Marcel, 1950, p. 212; cf. Burch, 1986, pp. 6-7)

In our institutional practice, the precedence of research "problems" is clearly evident, for example, when we caution $\mathrm{PhD}$ candidates that their task is not to solve the "ultimate questions of the universe." Typically, we do so in good faith, when the intent is to chide unfocused or overam- 


\section{University of Alberta}

bitious students. The implicit assumption, however, is that such questions are not legitimate research problems, insofar as they are not amenable to an "appropriate technique" that leads to a decisive resolution that can conveniently be written up. Where problems take precedence over questions, determinate answers likewise take precedence over all exploration of what is truly questionable in the subject matter itself. Nowadays, even in philosophy, traditionally charged to ponder the "ultimate" questions as a way of life, such transformations hold sway when, under the hegemony of formal calculi and metalinguistics, a purification of thinking into exact calculation and information processing is championed.

Insofar as research proceeds by positing and solving determinate problems within a predelineated sphere of objects, knowing as research requires ever greater specialization, both in terms of setting one field of research off from another and dividing each field into more specific problem sets.

This particularizing (specialization) is ... by no means simply the unfortunate concomitant of the increasing unsurveyability of the results of research. It is not a necessary evil, but an essential necessity of science as research. Specialization is not the consequence but the ground of the progress of all research. (Heidegger, 1950, p. 77).

The precedence of research problems and the specialization of research are thus essentially the same. They are based on a strategy of divide and conquer, one that is essentially exclusive, particularizing, and abstractive. It is this in turn that allows scientific research to amass results, the domains of investigation being set up in advance to reveal themselves entirely in manageable calculable forms. As results are amassed and put on hand in the store of knowledge (gathered more and more into the universal library of data banks), the university itself comes to be organized in the same way, that is, as a research business for the production of information, ideas, and techniques, with an appropriate division of labor, "rationalization," and five-year plans. In this situation, the measure of the researcher lies above all in measurable productivity and the marketability of results.

Though in this situation we are all aware of who among us is most "productive," knowing as research has itself no specific place or personality. Furthermore, this anonymity and universality are essential aspects of its social utility. For knowing as research proceeds according to abstract techniques that in principle can be wielded by anyone and that have universal application. Such techniques are unbiased, for their domain is everywhere and nowhere. They can be formulated into compendia and manuals that in principle are teachable. It is on these terms that the "teaching" half of our professional professorial duties tends to be organized, that is, in such a way as to disseminate established "results" 
and to train in techniques. Knowing as research is thus appropriately housed in institutions that are everywhere indifferently the same. Such institutions put methods and resources at our disposal, to be used and handed down, and "facilitate a plannable conjoining of types of methodology, that further the reciprocal checking and communication of results, and regulate the exchange of talents" (Heidegger, 1950, p. 77-78).

Yet knowing as research "does not simply amass results," it establishes, confirms, adapts, and verifies itself in its "on-going activity" (pp. 77-79). For each sphere of research, the method delineates in advance the essential character of the objects to be researched. In this way, it prescribes the procedures, types of equipment, and source materials appropriate to investigation and explanation, and guarantees in principle the legitimacy of its results. At the same time, the specific results contain possibilities for other procedures and avenues of investigation that press research on toward the exhaustive objective calculation of all that is.

On this account, then, the essence of science lies in knowledge as research and the essence of research lies in its methodological rigor. Rigor in turn consists in the establishment of procedures that ensure in principle the objectivity, falsifiability, and calculability of all results. These criteria can be ensured only because the method of research as such opens up a determinate sphere of objects for investigation by projecting in advance an essential ground plan of the reality to be investigated. "This projection sketches out in advance the manner in which the knowing procedure must bind itself and adhere to the sphere opened up. This binding adherence is the rigor of research" (Heidegger, 1950, p. 71). The objectivity of each field of inquiry is thus determined by the manner in which the field is posited discriminately in advance as an object. In this sense, what is preeminently "objective" is that which for scientific knowing is wholly discriminate and offers no residue of opacity or manifold of possible aspects, in other words, whatever can be reduced to numerical or formal relations. "Only that which becomes an object in this way is-is considered to be a being. We first arrive at science as research when the being of whatever is is sought in such objectness" (p. 80). Falsifiability and calculability are ensured on the same terms. The results of research are in principle falsifiable in terms of facts. Yet what can be encountered as a fact (and hence that in which their "factuality" lies) is determined in advance by the ground plan the method projects. Similarly, what is calculable presupposes essential uniformity such that the unknown can be reckoned on the basis of the known. This essential uniformity is ensured a priori insofar as the reality to be investigated is determined in advance as a homogeneous domain of objects through the methodological projection of a ground plan.

In the conception of knowing as research, the essential demand of rigorous methodology (i.e., to ensure the certainty of objective calculation) takes precedence over the essential character of the subject matter 


\section{University of Alberta}

itself. Assumed as a model for human science research, it would mean that the domain of what is essentially "human" is in principle determined in advance by the demands of methodology rooted in a prior projection of the "human" as a definite sphere of calculable objects. Insofar as methodologically it projects this domain uniformly, such research always already knows that its objects can differ significantly only in degree. Human science research would then be quantitative in the sense that it would calculate regularities and deviations within its own object-sphere by making use of specific mathematical techniques. Such research would also be experimental in a broad sense, that is, it would set up in advance the conditions under which a specific pattern of behavior would be susceptible to being plotted and determined by calculation. And it would be nomological, attempting ideally to trace facts back to rules and laws for future prediction and control and for projecting an exact picture of past behavior.

Those who align themselves under the banner of "human science research" would doubtless insist that their investigations are not properly characterized in the terms I have just outlined, agreeing with Gadamer (1975) that "the human sciences cannot be described adequately in terms of the idea of research and progress" (p. 252). Of course, the difficulty with such negative declarations is that they have unlimited scope and by themselves leave the true domain of human science research undefined. This lack of definition is reflected, I find, with distressing frequency in students' research proposals. Rejection of the prevailing model of scientific research is too often signaled by an appeal to any and every theorist who in any way questions this model, such theorists as Gadamer and Habermas, Derrida, and Heidegger being invoked without qualification as if they were wholly of one voice. More distressing is that rejection of this model in such proposals is often taken as license to exempt oneself from any careful methodological evaluation of one's discoveries, and thus from critical attention to the limits of the place from which one speaks. To meet our pedagogical responsibilities in such circumstances, what is needed is not just a more precise account of "how" human science research should proceed, but an understanding of "why" it must take the paths that it does. And this can be determined only in relation to the subject matter itself.

\section{The Human}

It is a joke almost as old as Western philosophy. Seeking an essential definition of human being, serious-minded philosophers proposed "twolegged animal." Waggish sophists pointed to a chicken. Undeterred, the philosophers refined their proposal: "Human beings are featherless bipeds"; whereupon the sophists plucked the chicken. Subsequent history reveals that the philosophers, ever victims of vocational gravity, were slow to get the point. On the assumption that it was a lack of conceptual precision that was being ridiculed, they continued to offer more refined, circumspective definitions (e.g., rational animal, thinking substance, 


\section{0th Anniversary of the Faculty of Education}

tool-making animal, etc.), striving to establish the specific difference that would mark out human being definitively from other creatures. Whether the defining characteristic was found in empirical or metaphysical properties, the same outlook prevailed. The task was to represent human being as one sort of being among others with specifically distinctive properties, defined in such a way as to constitute a determinate class of objects that could then be taken as a given (positum) for knowledge. Insofar as they seek an objective determination of human being as such, the "positive" sciences, including in that measure anthropology, psychology, and even philosophy, follow essentially the same course.

Human science finds a deeper point to the sophists' wit. It takes their joke to impugn the appropriateness of all objective definitions and categorical ascriptions for disclosing human being essentially, and hence the adequacy of all objectifying thinking, whether empirical or metaphysical, for charting the domain of the human in the terms proper to it. On this point, human science is at one with existential philosophy. "The means to elucidate human existence [Existenz] in thought must have a peculiar character, for human existence is neither an object in the world, nor holds as an ideal object" (Jaspers, 1948, p. 302). Because human being is not essentially an "object," it cannot be adequately rendered in abstract categorical terms, for that would be to reduce its selfhood to the property of a thing. What is called for instead is an existential/ontological characterization, that is, an account of how human being defines itself in its very being. "The question of 'what man is' is raised and answered in terms of what essentially he can be" (Heidegger, 1977a, p. 301n.), that is, in terms of the possibilities of his self-constitution. To objectifying thinking, this would be a matter of detailing abstractly the potentials of an objectively posited "human nature" or of assessing empirically our "specific" capabilities. In contrast, human science looks to the ways in which, in the concrete contexts that situate us (i.e., the worlds of tacit meaning that make up our hermeneutic situation and the ontic limits and possibilities disclosed therein), we come to be who we are, defining our own essence in virtue of what we come to realize of ourselves. This perspective accords with the subject matter itself to the extent that what we can be depends upon what we make of ourselves. Regarded in these terms, there is a determinate sphere of human science research only if human beings are essentially self-constituting and as such in each case distinguish themselves in their very being. It is phenomenology that secures this thesis systematically, demonstrating that human selfhood is in principle possible and intelligible only as a self-constituting process. In doing so, it also shows that this self-constituting process is our lived experience. All phenomenological theorizing, including that of human science, maintains a perspective on the lived human experience not just because this is a domain inevitably ignored by "objective" orientations, nor even because on the face of it to do so seems more respectful of what others actually think and feel. Rather, phenomenology maintains this 


\section{University of Alberta}

perspective because it holds that we are our lived experience. The sense of phenomenological method is to be found in this specific ontological thesis.

The immediate implications of this thesis for the phenomenological outlook, and thus by extension for phenomenological human science, can be quickly drawn. In showing that we are our lived experience and that lived experience is a self-constituting process, phenomenological analysis also shows that "an understanding of being is an ontological determination" of human being (Heidegger, 1977a, p. 12). It is in and through the process of lived experience that a self establishes its self-identity, and so is aware of itself as such. "Without the awareness, [there would be] no self-identity; but without self-identity the self would not be a self at all" (Fackenheim, 1961, p. 94, n. 50). It follows, then, that insofar as the self constitutes itself in lived experience, in the same process it "understands itself in its being ... and to some degree does so explicitly" (Heidegger, $1977 \mathrm{a}, \mathrm{p} .12$ ). In our very selfhood, then, our "being is an issue for us" (p. 12 ), even if as a matter of course we do not grasp this issue thematically. Yet, with this ontological concern, the self does not merely come to have an understanding of its being in the course of its lived experience. Rather, in the selfhood of the self, "being is understanding" (cf. Gadamer, 1976, p. 49 ; cf. Burch, 1989 , p. 208). It is on this correlation that both the phenomenological conception of "authenticity" (cf. Langan, in press) and the task of phenomenology as one of "explicit ontological self-interpretation" (Burch, 1989, p. 198) are based. Taken on these terms, the issue of one's being does not come down just to the mundane choices one makes, nor even the specific possibilities for such choices that are explicitly entertained. The question of what one does, in terms of which one tends to define oneself from day to day, is always already founded upon one's fundamental orientation to the world. Put colloquially, who one is depends upon where one is at. But here, too, "possibility stands higher than actuality" (Heidegger, 1977a, p. 38). For "where one is at," in terms of which is answered the question of "what essentially one can be," is rooted in the implicit unthematized possibilities of meaning inscribed in one's situation, the meanings in virtue of which actual choices and explicit interpretations can be entertained and made.

Though an issue of our selfhood, the "understanding of being" in lived experience is not a self-understanding divorced from all relation to other beings. Indeed, as the proximal locus and medium for transcendent meaning, our lived experience constitutes also our "engagement in the disclosure of beings as such" (p. 208). Now, if by being itself we mean "that on the basis of which beings are always already understood," then the lived experience in and through which we ourselves come to be also constitutes our basic ontological understanding of beings encountered within the world. 


\section{0th Anniversary of the Faculty of Education}

On this account, what is ultimately at issue for a phenomenologically oriented human science is the origination of meaning in virtue of which in the concrete situations of lived experience we come to be selves and that first founds all our encounters with things and people and hence all action, affection, objective cognition, and so forth. The topic is the domain circumscribed in lived experience by ontological understanding, a domain which as researchers we must in some sense always already share ourselves. Since this ontological understanding is an existential determination and not a generic property, its occurrence is "in each case mine," that is, personal and individual (Heidegger, 1977a, p. 41). Yet insofar as an actual world of things and other selves, as well as a tacit situating horizon of potential interpersonal meanings, belongs in each case to the understanding in lived experience, its truth is never simply idiosyncratic. Indeed, existentially/ontologically, idiosyncrasy presupposes communality. Accordingly, insofar as human science is concerned as phenomenology with the truth of lived experience, it is turned to individual people and circumstances in order above all to construe in its manifold forms the shared world of meaning that defines their communality (whether good or bad) and in relation to which the individuals come to be who they are.

\section{Science}

If we are to call such theorizing "scientific," a more inclusive notion of "science" is needed than that disclosed in the prevailing conception. Yet

in the face of the diversity of traditions that make up science, it may be dangerous to try to capture an essential point of agreement... Nonetheless ... what scientific traditions share is the passionate desire to attain better understanding whatever the subject of interest. (Barritt, 1986, p. 17)

Though helpful, this suggestion stipulates at best a necessary and not a sufficient condition of science. For whenever we reflect upon our experience, we typically do so at least in part because we desire to attain better understanding. Yet for that reason alone we would not say that all such reflection is science. It would be a further necessary condition of a science that within a particular domain it be able to discriminate with internal warrant which understanding is "better" from which is not. In this respect, every science is animated by a specific conception of "truth" and follows a specific methodological orientation. Yet even this is not sufficient to distinguish science as such. For even desultory, practical reflection has, if only implicitly, its characteristic paths and measures of truth from which it ventures discriminating judgments. Yet, unlike these other forms of reflection which in being discriminate proceed ad hoc from what is directly given in ordinary experience and practice, a science is further distinguished as such in that in and through its methodological orientation it first opens up a domain for systematic investigation by "reconstituting" the subject matter itself in essential terms. In this way, before all specific judgments and findings, it presumes in advance to 


\section{University of Alberta}

disclose the topic as a whole truthfully. It is this disclosure that predetermines for each science the manifold aspects of its scientificity, serving to ground its unity and systematic character, the nature of its rigor and verification, its concepts and appropriate evidence, even the nature of its teachability. Of course, in being faithful to the subject matter itself, the "constitution" of a science "is opposed to all free-floating constructions" (Heidegger, 1977a, p. 28). Yet, in going beyond the realm of ordinary experience and practice as a whole, it is also opposed to all isolated "adventitious findings."

Judged on these terms, human science could then properly be said to be distinctive as a science only if it were to stand originally in a distinctive disclosive relation to the domain of its subject matter. On the prevailing conception, as we have seen, each science establishes its respective domain by a fundamental objectification, presupposing in this a decision made on independent epistemological grounds concerning what can count as objective scientific knowledge. The faithfulness of such sciences to their subject matter is presumed to lie in this prior epistemological clarification and legitimation. On this basis is established the specific methodological procedures legitimate for investigating a sphere of beings and a determination of what the beings in that sphere can be in truth. What animates this conception of science is an initial fundamental skepticism regarding genuine knowledge, a skepticism that persists until the foundations of knowledge itself have been fixed. This approach is "positivist" in the broadest sense in that it investigates a subject matter accessible to investigation in virtue of how it is first posited as a given according to independent principles of scientific knowledge. In contrast, human science does not posit objects but explores the special ontological relation that obtains already in lived experience. In this regard, it presumes to take its methodological directive from the essence of subject matter itself. This relation is expressed by the ontological thesis I have been outlining, namely, that we are always already "understandingly" in the world, and that the domain of this "understanding" is itself the ultimate topic of human science research, marking out the limits of our original participation in truth. The epistemic doubts of human science are thus of a different order than those that obtain in other sciences. It is not a matter of securing objective knowledge of what is other and alien, but of exploring a fundamental meaning concealed in an understanding that belongs already to our very being. Here, questions of evidence and concept formation, of rigor and verification, are not problems of objective precision and certainty but questions of disclosive power. What is sought is a more inclusive, revealing understanding of where we stand in the world. In this respect, we see matters too superficially if we only regard experiences abstractly as something we simply have, to be isolated and when necessary controlled by specific techniques, rather than as part of an integral self-constituting process that makes up a person's whole way of being in the world. Yet we also misjudge the place of our reflections if 
we see this way of being as something which by prowess we can effectively change for others and not as something that each person must ultimately change for herself, a change which at best we can only thoughtfully facilitate. In this sense, human science has no usable doctrine to hand on and no techniques to impart.

In its distinctive scientific character, human science would seem nonetheless to be bound by inimical demands. On the one hand, as a concrete inquiry, it "must hold close to experience" (Merleau-Ponty, 1964b, p. 198), mindful of its ambiguity, complexity and spontaneity, maintaining a perspective on the world of everyday lived meanings. Likewise, as a humane inquiry, human science must also grant a perspective upon that world in terms of which we can better decipher what is appropriate to particular people in particular situations (cf. van Manen, 1986, p. 90). On the other hand, as a science, it must proceed systematically, reconstituting the subject matter essentially, disclosing and exploring the topic in its universality. Its investigative perspective is theoretical in a literal sense, that is, it looks from a distance upon experience as a whole in order to get the overall sense of it, a sense hidden to the actors in situ. In the coherent conjunction of these demands is presupposed a peculiar conception of truth, one that is unintelligible on the assumptions which inform the prevailing view of the sciences of human affairs. In that view, the concrete is equated with the particular and the particular with the factual, while the universal is a property or rule that extends indifferently over a range of particulars and is found by rigorous abstraction and generalization from a sample of that range seen in operation under controlled conditions. Theorizing from this perspective has direct practical use insofar as it purports to "know" objectively the "workings" of human behavior, such knowledge being intrinsically instrumental (cf. Jonas, 1966). Truth in this view lies in the epistemically assured determination and objective calculation of facts. In contrast, in the outlook of human science it is the factual particular taken as such that is abstract, whereas the concrete is realized in and as the universal, the universal in this conception being an integral meaning, a significant whole that encompasses and situates particulars in their factuality. Though without instrumental efficacy, human science theorizing has practical import insofar as it shows forth the domain of practical ends and injunctions more truly and so situates our practical dealings overall. The "truth" of such theorizing is not directly about factual particulars as such but about transcending meanings in virtue of which the facts of lived experience are first possible and intelligible. It is in these terms that the "scientific" procedures of human science research must be understood. Thus, whereas human science proceeds from individual cases by exemplification and anecdote, it is not this or that actual case as such that is at issue but an essential meaning which precedes and makes possible actual cases. In this respect, human science must free itself from "a confusion, endemic in the West since Plato at least, of the imagined with the 


\section{University of Alberta}

imaginary, the fictional with the false, making things out with making them up" (Geertz, 1988, p. 140). In this respect, the risk inherent in its procedure is not that human science will generalize illicitly from single cases, since generalization is not its task. It is rather that it will confuse the individual case that exists as such only in virtue of the systematic construction and inscription of phenomenological theorizing with actual cases with which one is familiar within lived experience, and so confuse everyday reflection with the essential understanding systematically worked out.

\section{Research}

The doubts that arise from consideration of the prevailing conception of scientific research concerning the appropriateness of the term "science" in characterizing what we do are just as great when it comes to the term "research." When we consider the record of this term's use, they become even greater.

The O.E.D. provides a disquieting history for the word "search." ... From the 1400 's on, "search" takes on a public, intrusive and corrective function. Searchers are described as examiners responsible for ascertaining contraband at customs, blasphemy in convents and the cause of death in corpses. (Grumet, 1985, p. 8)

If we extrapolate from this tradition, research into the domain of the human would amount to the systematic surveillance of human behavior, exposing it to official scrutiny in order to ensure that everything is in order and under control. ${ }^{9}$ To give this surveillance warrant, it comes under the auspices of objective truth and with the promise of human betterment through greater control and advertence of the vicissitudes and problems of social and personal life. Yet it is no respecter of persons. Behind its guise and promise, as Foucault (1979) has argued, knowing as surveillance serves, in a more diffuse, impersonal, and therefore elusive and so more effective way, the exercise of official power, "providing the rule, the order and the subordination that had previously been accomplished by the display of force" (Grumet, 1985, p. 9). That human science purports to break with this tradition for the sake of a concrete understanding more appreciative of persons and their situations need at this point hardly be said. Moreover, it is also evident by now that in making this break human science differs from this tradition both in what it claims to know of the human and how it comes by this knowledge. In this regard, the etymology of "research" permits a more felicitous reading (cf. Grumet, 1985). The term "research" comes to us via the French rechercher and the Old French recerchier from the Latin prefix re meaning "again" and the root circare meaning "to go about." Circare derives in turn from the noun circus meaning "circle" and by extension the place for viewing a spectacle from all sides. There is implicit in this etymology a hermeneutic sense that is still retained in the French (though lost in the translation to "scientific" English). As reflected, for example, in Proust's $\grave{A}$ la recherche $d u$ temps perdu (1987), the term rechercher does not 
suggest the "objective" scrutiny of an other's behavior, but the personal recollection of an essential meaning in terms of which the integral but concealed truth of an experience can be recovered. The "re" prefix implies "again and in a different way" and the circularity that of the place and essence of understanding itself. As research, human science repeats or recapitulates a lived experience to discern the animating motifs or themes that typically give it its unity and sense (cf. van Manen, 1990). Yet in both its meaning and direction, this "sense" is constituted in a concrete context, oriented by all of the situating factors that are appropriated into lived experience in the course of its self-constitution. Thus the essential circularity of research derives from the fact that what research makes explicit must in some sense be already understood in our selfhood, yet as this understanding is not explicitly self-contained, needs to be explored.

Yet, in rejecting the tradition of "objective" research, we should not allow ourselves to become smug about the place of human science. For, to some, it may well look as if the practitioners of human science research, for all their disclaimers, undertake an even more sinister form of surveillance than that which they explicitly reject.

Not limiting themselves to what is in principle observable though usually hidden from public view, they intrude into the personal lives of others, enjoining others to share candidly their experiences, as if everyone, researchers and participants alike, had the same stake in the situation and in these personal disclosures. In this way, they proceed to make everything public, assuming in advance a communality and intimacy in which only the cynical and two-faced would keep something to themselves. ${ }^{10}$

If this were true, it would be a damning criticism; and that it has at least the appearance of truth in specific cases, no one is likely to deny. Yet, qua phenomenological, such research would then fall short on its own terms. In this regard, it does not suffice just to point out again that the topic of phenomenological research is not individual subjects and their inner psychic lives but lies in the meanings that situate selves and constitute the horizon of a shared world. Nor does it suffice to point out that in the pursuit of truth, phenomenological research must not take for granted the meaning of communality, or the relation of public and private. Rather, it must also be reiterated that the very possibility of phenomenological research depends upon one's original participation in the topic of research, and hence that ideally it is incumbent upon a rigorous phenomenology to consider explicitly the truth of that participation in both its ontic and ontological dimensions. Methodologically, in the manner of one's participation in a shared context lies both the initial questionableness of one's questions and the "ethical" warrant of one's research. ${ }^{11}$

\section{Human Science and Philosophy}

"A human science researcher is a philosopher, or someone who has rubbed shoulders with the philosopher" (van Manen, 1989a, p. 237). 


\section{University of Alberta}

There is an obvious sense in which this must be so. To the extent that human science is a reflective discipline, the human scientist must proceed philosophically, in order to establish the epistemological grounds and implications of her research and to chart the essential place of her theorizing. To that end, it would seem "important for the human science researcher ... to know something of the philosophic traditions" (p. 249). But this is not the whole story. Insofar as it is a truly reflective discipline, philosophic consideration of the place of its research and the meaning of its assumptions and discoveries is not just an epistemological adjunct to human science, a philosophical prologue or afterthought. It is, rather, an intrinsic dimension of the very process of research. Yet herein lies the rub. Human science cannot take over a method from phenomenology to the exclusion of phenomenology's philosophical aims and content. For there can truly be no such division in the domain of phenomenology itself, nor then truly any such borrowing. Thus, insofar as it is phenomenological, human science research does not make use of philosophy to investigate concrete lived experience; it is a concrete philosophy. It discloses essentially individual instances of a type in the domain of lived experience, seeking to reveal in each type the manner of our participation in truth. Its content is existential/ontological rather than simply empirical; its guiding aim is the search for truth rather than directly for practical competence; and its method is inseparable from the essence of what it discloses.

\section{A Retrospective Glance}

I have ventured to explore in principle the meaning and ground of phenomenology's methodological orientation and on that basis to chart the essential place of any human science research that takes its directive from that orientation. My concern was to resolve my own philosophical "ineptitude" in order to find a basis from which to begin to mediate the opposing outlooks and expectations of my students. It belongs to such reflection, however, (as to all phenomenology) that in the very process of disclosing this or that aspect of the topic, it inevitably leaves much else, both within and without the domain it maps, unexplored. At this point, then, my philosophy students are apt to be even more exercised by theoretical issues. Moreover, in plotting the formal conditions and boundaries of phenomenology and human science, my efforts still have not addressed any specific practical concerns, neither existential questions themselves, nor particular issues of methodological procedure. At this point, then, my more practically oriented students are apt to be even more impatient with having postponed what in their view comes first in any case. The task now is to curb the abstract metacritical enthusiasms of the one group by emphasizing the basis of all phenomenological theorizing in one's participation in a situation; and to assuage the impatience of the other group by showing the ways in which the topic of such theorizing does come before the practical. These, however, are tasks for a concrete pedagogical practice. At least now, I hope, I am more 


\section{0th Anniversary of the Faculty of Education}

assured of the theoretical ground on which we come, both as teachers and students, to meet them.

\section{Notes}

1. For this distinction between the "correct" and the "true" see Heidegger, 1977b, p. 6. "The correct always fixes upon something pertinent in what is under consideration," whereas the "true comes to pass [sich ereignet] only where ... the matter at issue is uncovered in its essence." See also Burch, 1989, pp. 199-200 and infra, p. 8. On these terms, the correct is possible only insofar as the matter at issue can be objectively determined. Where the essence of the matter cannot be so determined and hence where it cannot be captured once and for all by a perspicuous concept, idea or principle, neither can its truth be simply pinned down.

2. In this regard, for example, Nietzsche writes: "The degree and kind of a man's sexuality [Geschlechtlichkeit] reaches up into the ultimate pinnacle of his spirit" $(1966$, p. 81). If true, this would seem to imply that even one's philosophizing has an inexorable "sexual" dimension that serves to inform one's basic insights. (On the elusive term "Geschlect" and its "philosophical" importance see Derrida [1983]). Not surprisingly, it is contemporary feminist theorists who have been most attuned to the positive and negative aspects of this potential and who, so far, have gone furthest to develop its implications for the universality of philosophic thought. Moreover, though sympathetic to the typically male-written phenomenologies of embodiment, it is the feminist theorists who are also quick to point out that talk of "the body" is not the same as talk of bodies-particular, sexed, excretive. In contrast, because he insists on the "ontological difference" and the priority of ontological over ontic truth, Heidegger (1969) rejects these implications and gestures in principle. "Selfhood is neutral toward 'being an I' and 'being a thou,' and even more so toward 'sexuality' [Geschlechtlichdeit], since it is what makes them all possible in the first place. All essential propositions of an ontological analytic of Dasein in human being treat Dasein in its neutrality" (p. 87). The last word on these issues (assuming that the "last word" is not a "phallocentric" imposition) has yet to be given.

3. In his revealing study of "the Walkman world," Rainer Schönhammer (1989) writes: "The one statement of Husserl I absolutely agree with is: 'To the things themselves'- even if I equally strongly disagree with his belief that we can bracket reality the way he pretended to do it" (p. 136). Yet to reject Husserl's belief about what can and should be "bracketed" is to reject also his understanding of just what "the things themselves" truly are.

4. Husserl's talk of "monads" is a deliberate borrowing from Leibniz put to a phenomenological purpose. In Leibniz's metaphysics, each monad, or what is the same, "each simple substance, is in virtue of its nature a living mirror of the whole universe according to its own point of view" (Leibniz, VII, p. 411, n. 87). Yet only those possible "points of view" that are "compossible" attain existence (VII, pp. 289-290). Thus the totality of existing monadic viewpoints does not reflect "many different universes but different perspectives of a single universe" (VI, p. 464).

Though Husserl bases his own argument on the intentional structure of consciousness, he uses Leibnizean language to conclude that "each monad," or each ego-self, "having the status of a concrete possibility, predelineates a compossible universe, a closed 'world of monads'" (1970a, p. 141).

5. One finds a rough analogue to this correlation in de Saussurean linguistics (1959).

De Saussure maintains that a prior general system of articulate relationships (langue) precedes and makes possible every isolated speech-act or utterance (parole), and yet this system has no concrete existence of its own, except as realized in the piecemeal acts of speech. Between language and spech, then, there is at once difference, interdependence and priority.

6. In contrast, the mainstream of Western philosophy typically holds that what a self does, whether it be conceived substantially (e.g., Descartes), empirically (e.g., Hume) 


\section{University of Alberta}

or transcendentally (e.g., Husserl), is consequent on its being, or in other words, that in order to act in any sense there must already be something to do the acting (cf. Fackenheim, 1961, pp. 29-30). It also conceives of the being of the self (i.e., that which determines the self as such) in roughly the same way, that is, in terms of objectively representable attributes or qualities which all entities that are selves possess as such. Taken together, these theses effectively block an original understanding of selfhood and intersubjectivity, since they rule out ex hypothesi all mutuality that is anything more than either a given self's construct (whether that be "intentional" or inferential) or a set of internal relations that obtain among selves according to the properties they possess.

7. I am paraphrasing here Kierkegaard's (1959) remarkable description of self-choosing in Either/Or (pp. 218-220), which is quoted at length in Fackenheim, 1961, pp. 84-85, n. 47).

8. Thus, phenomenological theorizing undercuts the usual debates in the philosophy of the social sciences concerning methodological "individualism" and "holism." In the former view, roughly sketched, our communality is seen in terms of what is socially created through the external relations among discrete individuals, the resultant social whole being simply the sum of its parts. In the latter view, the social whole is seen always to be more than the sum of what the participating individuals accomplish singly, as one might say, for example, by analogy that the combination $\mathrm{H}_{2} \mathrm{O}$ amounts to more than the external sum of two hydrogen and one oxygen molecules. (To my knowledge, this analogy was first offered by Durkheim [1938] by way of arguing that the "synthesis constituting every society yields new phenomena, differing from those which take place in individual consciousnesses" [p. xixiii]). Yet insofar as each of these views takes the individual "subject" as a primary given and then asks how subjects are socially related, neither one is phenomenologically adequate. The task of phenomenology is to discover the transcending and situating "intersubjective" context in virtue of which subjects come to be subjects in the first place. Though closer to holism, phenomenology would reject the chemical analogy, not because it would deny that the combination $\mathrm{H}_{2} \mathrm{O}$ is more than a mere sum of its elements, but because, unlike social actors, these elements can exist independently before all combination.

9. In this regard, I was once told by a Celtic scholar at the University of Edinburgh that the principle word for "research" in Gaelic, the language of a people perennially under siege, is rannsachadh, which comes from the verb rannsaich, an Old Norse derivative from rann (house) and sakka (to search) and means literally "a thorough search of someone's house to look for what she has hidden." The same etymology is evident in the English word "ransack." Yet, as with the English word "research," a more felicitous reading could be offered, insofar as human science research is at root a "seeking or searching" of one's own "home."

10. My paraphrase, with permission, of a personal communication from Dr. Howard Hopkins, Ministry of Human Rights, Government of Alberta.

11. In this regard, I am told by students who attended Alan Blum's seminar for a summer session at the University of Alberta, that as each student would outline his or her research project, Blum would challenge them in turn by asking: "This is what you are curious about; but what is your question?" If I understand Blum's challenge correctly, what he asks for is not just a more precise interrogative statement of a theme, but what existentially makes this theme particularly questionable for the researcher, and so brings to light one's prior place in what is being questioned.

\section{References}

Arendt, H. (1978). Thinking. New York: Harcourt Brace Jovanvich.

Aristotle. (1962). Nichomachean ethics (M. Ostwald, Trans.). Indianapolis:

Bobbs-Merrill.

Aron, R. (1975). History and the dialectic of violence. Oxford, UK: Blackwell.

Barber, M.D. (1989). Edmund Perry, The distribution of knowledge, and the looking glass of race. Phenomenology + Pedagogy, 7, 218-31. 


\section{0th Anniversary of the Faculty of Education}

Barritt, L.S. (1986). Human science and the human image. Phenomenology + Pedagogy, 4, 14-21.

Barritt, L.S., Beekman, T., Bleeker, H., \& Mulderij, K. (1983). The world through children's eyes: Hide and seek \& peekaboo. Phenomenology + Pedagogy, 1, 140-161.

Beekman, A.J. (1983). Human science as a dialogue with children. Phenomenology + Pedagogy, 1, 36-44.

Bergum, V. (1989). Woman to mother: A transformation. Granby, MA: Bergin \& Garvey. Bloom, A. (1988). The closing of the Americian mind. New York: Random House.

Bourdieu, P. (1977). Outline of a theory of practice. Cambridge, UK: Cambridge University Press.

Burch, R. (1985). A reflection on art and truth: Merleau-Ponty and Heidegger. Proceedings of the Merleau-Ponty Circle, $X$ (pp. 403-420).

Burch, R. (1986). Confronting technophobia: A topology. Phenomenology + Pedagogy, 4, 3-21.

Burch, R. (1989). On phenomenology and its practices. Phenomenology + Pedagogy, 7, 187-217.

Burch, R. (1990). Phenomenology/Lived Experience: Taking a measure of the topic. Phenomenology + Pedagogy, 8, 130-160.

Danner, H. (1986). Senses and meaning, quality and education: Some notes on a workshop. Phenomenology + Pedagogy, 4, 29-36.

de Beauvoir, S. (1960). La force de l'age. Paris: Gallimard.

Derrida, J. (1983). Geschlecht: sexual difference, ontological difference. Research in Phenomenology, 13, 65-83.

de Saussure, F. (1959). Course in general linguistics. New York: McGraw-Hill.

Descartes, R. (1985). The philosophical writings of Descartes. (J. Cottingham, R.

Stoothoof, D. Murdoch, Trans.). Cambridge: Cambridge Univeristy Press.

Durkheim, E. (1938). The rules of sociological method. New York: The Free Press.

Fackenheim, E.L. (1961). Metaphysics and historicity. Milwaukee, MN: Marquette University Press.

Fackenheim, E.L. (1967). Quest for past and future. Boston: Beacon Press.

Feuerbach, L. (1959) Zur Kritik der Hegelischen Philosophie. Philosophische Kritiken und Grundsütze. Stuttgart: Günther Holzboog.

Foucault, M. (1979). Discipline and punish. New York: Vintage Books.

Gadamer, H.G. (1975). Truth and method. New York: Seabury Press.

Gadamer, H.G. (1976). Philosophical hermeneutics. Berkeley, CA: University of California Press.

Geertz, C. (1983). Local knowledge: Further essays in interpretive anthropology. New York: Basic Books.

Geertz, C. (1988). Works and lives: The anthropologist as author. Cambridge, UK: Polity Press.

Grumet, M.R. (1985, December 9-11). The politics of personal knowledge. Paper presented to the Symposium, Classroom Studies of Teachers' Personal Knowledge, OISE., Toronto, ON.

Hegel, G.W.F. (1977). Hegel's phenomenology of spirit. Oxford, UK: Oxford University Press.

Hegel, G.W.F. (1978). Hegel's philosophy of subjective spirit. Boston, MA: Reidel.

Heidegger, M. (1950). Holzwege. Frankfurt am Main: Klostermann.

Heidegger, M. (1957). Identität und Differenz. Pfullingen: Neske.

Heidegger, M. (1967). What is a thing? Chicago, IL: Henry Regnery.

Heidegger, M. (1967). Wegmarken Frankfurt: Klostermann.

Heidegger, M. (1969). On the essence of reasons. Evanston, IL: Northwestern University Press.

Heidegger, M. (1971). Poetry, language and thought. New York: Harper \& Row.

Heidegger, M. (1972). On time and being. New York: Harper \& Row.

Heidegger, M. (1977a). Sein und Zeit. 13 Aufl. (with the author's marginal notes). Tübingen: Niemeyer. 


\section{University of Alberta}

Heidegger, M. (1977b). The question concerning technology and other essays. New York: Harper \& Row.

Heidegger, M. (1978). Metaphysiche Anfangsgründe der Logik. Frankfurt: Klostermann. Husserl, E. (1965). Phenomenology and the crisis of philosophy. New York: Harper \& Row.

Husserl, E. (1969). Formal and transcendental logic. The Hague: Martinus Nijhoff.

Husserl, E. (1970a). Cartesian mediations: An introduction to phenomenology. The Hague: Martinus Nijhoff.

Husserl, E. (1970b). The crisis of European sciences and transcendental phenomenology. Evanston, IL: Northwestern University Press.

Ihde, D. (1979). Technics and praxis. Boston, MA: Reidel.

Jaspers, K. (1948). Philosophie, 2. Auf. Berlin-Göttingen-Heidelberg: Springer Verlag. Jonas, H. (1966). The practical uses of theory. The phenomenon of life. New York: Dell. Kant, I. (1929). The critique of pure reason. New York: St. Martin's Press.

Kant, I. (1970). Metaphysical foundations of natural science. New York: Bobbs-Merrill.

Kierkegaard, S. (1959). Either/Or. New York: Doubleday \& Co.

Kockelmans, J. (1967). A first introduction to Husserl's phenomenology. Pittsburgh: Duquesne University Press.

Langan, T.D. (1984). Phenomenology and appropriation. Phenomenology + Pedagogy, 4, $1-12$.

Langan, T.D. (in press). Tradition and authenticity: Personal and social development toward oecumenic wisdom.

Leibniz, G.W. (1890). Die philosophischen Schriften von G.W. Leibniz. ed. C. Gerhardt. Berlin.

Marcel, G. (1950). The mystery of being, I. New York: Gateway Books.

Macmurray, J. (1956). The self as agent. London: Faber \& Faber.

Macmurray, J. (1961). Persons in relation. London: Faber \& Faber.

Merleau-Ponty, M (1962). Phenomenology of perception. London: Routledge \& Kegan Paul.

Merleau-Ponty, M. (1964a). Le visible et l'invisible. Paris: Gallimard.

Merleau-Ponty, M. (1964b). Signes. Paris: Gallimard.

Meyer-Drawe, K. (1986). Kaleidoscope of experiences: The capability to be surprised by children. Phenomenology + Pedagogy, 4, 48-55.

Nietzsche, F. (1966). Beyond good and evil: Prelude to a philosophy of the future. New York: Vintage Books.

Plato. (1961). Letter VII. Plato: The collected dialogues. Hamilton, E., \& Cairns, H.. (Eds.). Princeton, NJ: Princeton University Press, 1574-1598.

Proust, M. (1987). A la recherche du temps perdu. Paris: Gallimard.

Sartre, J.P. (1938). La nausée. Paris: Gallimard.

Schmidt, W.H.O. (1983). Piaget and the egocentric tradition. Phenomenology + Pedagogy, 1, 162-171.

Schönhammer, R. (1989). The Walkman and the primary world of the senses. Phenomenology + Pedagogy, 7, 127-144.

Schouls, P.A. (1987). The imposition of method. Oxford: Oxford University Press.

Schutz, A. (1967). The phenomenology of the social world. Evanston, IL: Northwestern University Press.

Schutz, A. (1975). The problem of transcendental intersubjectivity in Husserl. Collected papers III: Studies in phenomenological philosophy. The Hague: Martinus Nijhoff.

Spiegelberg, H. (1982). The phenomenological movement. The Hague: Nijhoff. van Manen, M. (1986). We need to show our human science is a relation of pedagogy.

Phenomenology + Pedagogy, 4, 78-93.

van Manen, M. (1989a). By the light of anecdote. Phenomenology + Pedagogy, 7, 232-253.

van Manen, M. (1989b). Editorial. Phenomenology + Pedagogy, 7, 1-2. van Manen, M. (1990). Researching lived experience: Human science for an action sensitive pedagogy. London, ON: Althouse Press; New York: SUNY Press. 